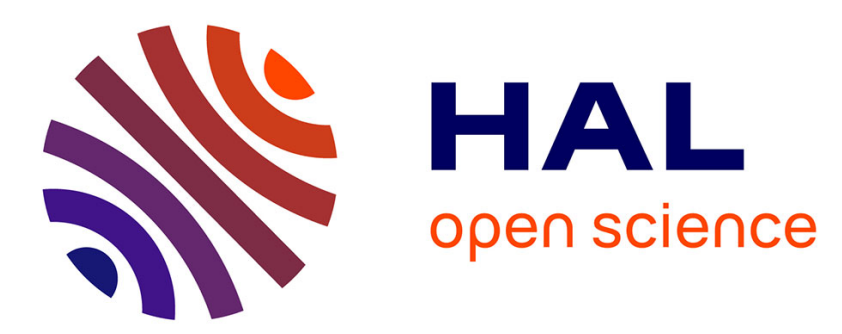

\title{
Analytical study for the development of a new warping function for high order beam theory
}

Ismail Mechab, Noureddine El Meiche, Fabrice Bernard

\section{To cite this version:}

Ismail Mechab, Noureddine El Meiche, Fabrice Bernard. Analytical study for the development of a new warping function for high order beam theory. Composites Part B: Engineering, 2017, 119, pp.18-31. 10.1016/j.compositesb.2017.03.006 . hal-01508439

HAL Id: hal-01508439

https://hal-univ-rennes1.archives-ouvertes.fr/hal-01508439

Submitted on 5 Jul 2017

HAL is a multi-disciplinary open access archive for the deposit and dissemination of scientific research documents, whether they are published or not. The documents may come from teaching and research institutions in France or abroad, or from public or private research centers.
L'archive ouverte pluridisciplinaire HAL, est destinée au dépôt et à la diffusion de documents scientifiques de niveau recherche, publiés ou non, émanant des établissements d'enseignement et de recherche français ou étrangers, des laboratoires publics ou privés. 


\title{
Analytical study for the development of a new warping function for high order beam theory
}

\author{
Ismail Mechab $^{1,2}$, Noureddine El Meiche ${ }^{1,3}$, Fabrice Bernard ${ }^{4 *}$
}

${ }^{1}$ University of Mascara, Mascara 29000, Algeria.

${ }^{2}$ LMPM, Department of Mechanical Engineering, University of Sidi Bel Abbes, Sidi Bel Abbes 22000, Algeria.

${ }^{3}$ LGCE, University of Sidi Bel Abbes, Sidi Bel Abbes 22000, Algeria.

${ }^{4}$ INSA Rennes, LGCGM, 20 avenue des Buttes de Coësmes, 35708 Rennes cedex 7, France.

*Corresponding author: Fabrice.Bernard@insa-rennes.fr 


\section{Abstract $\quad$ ACCEPTED MANUSCRIPT}

This paper presents an analytically and numerical study of the warping phenomenon in short beams, thick plates and anisotropic materials. A transverse shear higher order theory is considered. The equilibrium equations are inspired by the principle of virtual work that has permitted to establish the boundary conditions. The analytical development of a new warping function is inspired by others works found in the literature for three-point bending. The stabilization of this new iterative function under a uniformly distributed pure bending load is used for any type of structure. Analytical results are compared with other existing models in the literature and a simulation using the finite element method.

Keywords: Warping function, Higher order theory, Principle of virtual work, three-point bending, Finite element method. 


\section{Introduction}

The use of composite materials in industrial applications tends to increase these last years, and those in all industries: automotive, aerospace, marine, rail and civil engineering. Performance in terms of mass gain, mechanical properties and fabrication offer numerous possibilities of applications.

A variety of beam and plate theories have been proposed [1,3], in which the plates are generally subjected to various types of mechanical loads. It is worthwhile here to present some historical developments in the plate theory since many of them are considered in this work.

The classical beam theory is based on a linear distribution of displacements in the thickness. The assumption made is the one of Euler-Bernoulli plane stress, deformation due to transverse shears is neglected. Normal force remains straight and is perpendicular to the mean deformed surface.

The first-order shear deformation beam theory, which assumes the constant shear strain distribution throughout the beam thickness, violates the shear traction-free condition on the top and bottom surfaces of the beam. The shear correction factor is then employed to correct the discrepancy between the results derived from the exact theory and the solutions obtained via first-order shear deformation theory [4,5].

Several authors have proposed theories of higher order to overcome the limitations of firstorder theories. The models are based on a non-linear distribution of the field in the thickness. The Vlasov-Levinson-Reddy [6-8] theory, also called Third order Shear Deformation Theory (TSDT), among other third order theories, proposes a kinematic field with a third-order polynomial dependence on $\mathrm{z}$, motivated by the respect of the nullity of transverse shear at top and bottom faces of beams and plates. Bickford, Krishna Murty, Baluch et al., Kant and Bhimaraddi and Chandrashekhara have presented parabolic shear deformation theories (PSDT) assuming a higher variation of axial displacement in terms of thickness coordinates [9-13]. Touratier and B.Mechab [14-15] propose the enriched "sinus" model which is different from other models of higher order since it does not use a polynomial function. A trigonometric function is introduced to model the distribution of shear stress in the thickness. Ghugal and Shimpi [16] developed a variationally consistent refined trigonometric shear deformation theory (TSDT) for flexure and free vibration of thick isotropic beams. Recently, Afaq et al. proposed an exponential model with a rich cinematics [17]. Aydogdu, Ghugal, Mechab, El Meiche, Ait Atmane, Challamel and Mantari, Sobhy studied the effect of shear deformation theory for flexure and vibration of thick isotropic, composites and FGM structures using a hyperbolic model [18-27]. 
Many studies have been conducted on composite materials on the mechanical behavior at the macroscopic scale. On the other hand, the continuous development of sensors and field measurement techniques used to go further in the analysis of complex structures and composite materials. Several models have been also developed for the stability analysis of thin-walled open sections from Vlasov's model [28]. Barsoum, Feo et al., Mancusi and Minghini presented a finite element model for the stability analysis of bisymmetric I section $[29,33]$.

Other studies examine the development of analytical models, numerical and experimental modelling for warping of anisotropic structures, such as composite structures, due to transverse shear stresses. Many studies have been conducted on the mechanical behavior of composite materials at the macroscopic scale. In parallel to the analytical studies, experimental works with the development of new detection techniques and experimental fields measurements are carried out to analyse the effects of transverse shear [34]. Dufort used an optical technique to capture the displacement field on laminated beams subjected to three points bending. Surrel has developed an optical method namely the grid method, based on the measurement of displacements and deformations fields in the sample thickness [35-37].

The objective of this work is to study the short composites beams warping phenomenon and the development of a new warping function. Based on the work of Dufort, an iterative function in three-point bending depending on the geometrical and material characteristics of the beam is developed. This study is an improvement of Dufort work and proposes stabilization procedure of the iterative function under bending with uniform load.

\section{Governing equations of rectangular beams}

The displacements of a material point located at $(\mathrm{x}, \mathrm{z})$ in the beam may be written as

$$
\left\{\begin{array}{l}
\mathrm{u}(\mathrm{x}, \mathrm{z})=-\mathrm{zw}_{, \mathrm{x}}(\mathrm{x})+\Phi(\mathrm{z}) \gamma_{\mathrm{xz}}^{0}(\mathrm{x}) \\
\mathrm{w}(\mathrm{x}, \mathrm{z})=\mathrm{w}(\mathrm{x})
\end{array}\right.
$$

Where $\mathrm{w}(\mathrm{x}, \mathrm{z})$ represents the middle surface displacement components along the $\mathrm{x}$ and $\mathrm{z}$ axes, respectively, and $\gamma_{\mathrm{xz}}^{0}(\mathrm{x})$ is the transverse shear strain measured on the mean-line

$$
\gamma_{\mathrm{xz}}^{0}(\mathrm{x})=\mathrm{w}_{, \mathrm{x}}(\mathrm{x})-\phi^{0}(\mathrm{x})
$$


Where $\phi^{0}(\mathrm{x})$ is the total section rotation measured on the mean-line. $\Phi(\mathrm{z})$ is an odd function of $\mathrm{z}$ only. The shape function $\Phi(\mathrm{z})$ is to be specified a posteriori $[2,38]$. It may be chosen such that

$$
\left.\Phi^{\prime}(\mathrm{z})\right|_{\mathrm{z}= \pm \frac{\mathrm{h}}{2}}=0, \int_{\mathrm{z}=-\frac{\mathrm{h}}{2}}^{\mathrm{z}=\frac{\mathrm{h}}{2}} \Phi(\mathrm{z}) \mathrm{dz}=0
$$

Where the prime (') denotes differentiation with respect to $\mathrm{z}$. It becomes therefore clear that, through its derivative, the a posteriori specified function $\Phi(\mathrm{z})$ will determine the through thickness trial distribution of the transverse shear strain. Most of the solutions shown were based on the choice of a shape function $\Phi(\mathrm{z})$ that is consistent with the so-called higher-order shear deformation beam theory polynomial shear deformation beams theory PSDBT and sinusoidal shear deformation beams theory SSDBT. In some case, the classical beam theory (CLBT) has also been used for comparison purposes as well as a first-order shear deformation beam theory (FSDBT). In more details, the shape function employed for each theory is as follows:

$$
\begin{aligned}
& \text { CLBT }: \Phi(\mathrm{z})=0 \\
& \text { FSDBT }: \Phi(\mathrm{z})=\mathrm{z} \\
& \text { PSDBT }: \Phi(\mathrm{z})=\mathrm{z}\left(1-4 \mathrm{z}^{2} / 3 \mathrm{~h}^{2}\right) \\
& \text { SSDBT }: \Phi(\mathrm{z})=\mathrm{h} / \pi \sin (\mathrm{z} \pi / \mathrm{h})
\end{aligned}
$$

The strain components compatible with the displacement field in Eq. (1) are

$$
\left\{\begin{array}{l}
\varepsilon_{\mathrm{x}}(\mathrm{x}, \mathrm{z})=-\mathrm{zW}, \mathrm{xx} \\
\gamma_{\mathrm{xz}}(\mathrm{x}, \mathrm{z})=\Phi_{, \mathrm{z}}(\mathrm{z}) \gamma_{\mathrm{xz}}^{0}(\mathrm{x})
\end{array}\right.
$$

An orthotropic elastic constitutive law is considered in the following form:

$$
\sigma_{\mathrm{x}}=\overline{\mathrm{Q}}_{11} \varepsilon_{\mathrm{x}} \text { and } \tau_{\mathrm{xz}}=\overline{\mathrm{Q}}_{55} \gamma_{\mathrm{xz}}
$$

where $\overline{\mathrm{Q}}_{11}$ is the elasticity modulus in the axial direction (denoted by $\mathrm{E}$ for isotropic beams) whereas $\overline{\mathrm{Q}}_{55}$ is the transverse shear modulus of the orthotropic beam (denoted by $\mathrm{G}$ for isotropic beams).

The strain energy $\pi$ of a beam of length $L$ with an area of cross section denoted A can be defined by the volumetric integral:

$$
\pi=\iiint_{\mathrm{V}}\left(\sigma_{\mathrm{x}} \varepsilon_{\mathrm{x}}+\tau_{\mathrm{xz}} \gamma_{\mathrm{xz}}\right) \mathrm{dAdx}
$$

Introducing the strains values of Eq. (5) into Eq. (7), the energy functional can be expressed in terms of the generalized displacements by: 


$$
\pi=\iiint_{\mathrm{V}} \sigma_{\mathrm{x}}\left[-\mathrm{zW}, \mathrm{W}_{\mathrm{x} x} \mathrm{C}(\mathrm{x})+\Phi(\mathrm{z}) \gamma_{\mathrm{xz}, \mathrm{x}}^{0 \mathrm{~A}}(\mathrm{x})\right]+\tau_{\mathrm{xz}}^{\mathrm{R}}\left[\Phi^{\prime}(\mathrm{z}) \gamma_{\mathrm{xz}}^{0}(\mathrm{x})\right] \mathrm{dAdx}
$$

The stiffness parameters can be introduced in the following format:

$$
\left\{\begin{array}{l}
\iint_{\mathrm{A}} \overline{\mathrm{Q}}_{11} \mathrm{z}^{2} \mathrm{dA}=\mathrm{c}_{1} \\
\iint_{\mathrm{A}} \overline{\mathrm{Q}}_{11} \mathrm{z} \Phi(\mathrm{z}) \mathrm{dA}=\mathrm{c}_{2} \\
\iint_{\mathrm{A}} \overline{\mathrm{Q}}_{11} \Phi(\mathrm{z})^{2} \mathrm{dA}=\mathrm{c}_{3} \\
\left.\iint_{\mathrm{A}} \overline{\mathrm{Q}}_{55} \Phi, \mathrm{z}\right)^{2} \mathrm{dA}=\mathrm{c}_{4}
\end{array}\right.
$$

The values of the stiffness parameters are given in Table 1. In the general case, these higherorder shear beam models have four stiffness parameters.

The variation of the internal energy functional (Eq. (8)) leads to the variational equality of the higher-order model:

$$
\delta \pi=\int_{0}^{\mathrm{L}}\left(\mathrm{M} \delta \mathrm{w}_{, \mathrm{xx}}+\mathrm{V} \delta \gamma_{\mathrm{xz}}^{0}+\tilde{\mathrm{M}} \delta \gamma_{\mathrm{xz}, \mathrm{x}}^{0}\right) \mathrm{dx} \text { with }\left(\begin{array}{l}
\mathrm{M} \\
\mathrm{V} \\
\tilde{\mathrm{M}}
\end{array}\right)=\left(\begin{array}{ccc}
\mathrm{c}_{1} & 0 & -\mathrm{c}_{2} \\
0 & \mathrm{c}_{4} & 0 \\
-\mathrm{c}_{2} & 0 & \mathrm{c}_{3}
\end{array}\right)\left(\begin{array}{l}
\mathrm{w}, \mathrm{xx} \\
\gamma_{\mathrm{xz}}^{0} \\
\gamma_{\mathrm{xz}, \mathrm{x}}^{0}
\end{array}\right)
$$

$\mathrm{M}$ and $\mathrm{V}$ are the local bending moment and shear forces. $\tilde{\mathrm{M}}$ can be considered as a higherorder moment. Within the framework of classical beam theories, loads prescribed on the beam can be of different types as recalled in Fig. 1: distributed load and concentrated force. Assuming that the external loads are applied at $\mathrm{x}=\mathrm{L}$, the total energy functional is then written as:

$$
\mathrm{U}=\int_{0}^{\mathrm{L}}\left(\mathrm{M} \delta \mathrm{w}_{\mathrm{xx}}+\tilde{\mathrm{M}} \delta\left(\mathrm{w}_{, \mathrm{xx}}-\phi_{, \mathrm{x}}^{0}\right)+\mathrm{V} \delta\left(\mathrm{w}_{, \mathrm{x}}-\phi^{0}\right)\right) \mathrm{dx}-\int_{0}^{\mathrm{L}} \mathrm{q} \delta \mathrm{wdx}-\mathrm{F}_{\mathrm{z}} \delta \mathrm{w}(\mathrm{L})
$$

The governing equations of equilibrium can be derived by using the principle of virtual displacements. The equilibrium equations associated with the present unified shear deformation theory are:

$$
\left\{\begin{array}{l}
\delta \phi^{0}: \widetilde{M}_{, x}-V=0 \\
\delta \mathrm{w}: \mathrm{M}_{, \mathrm{xx}}+\widetilde{\mathrm{M}}_{, \mathrm{xx}}-\mathrm{V}_{, \mathrm{x}}-\mathrm{q}=0
\end{array}\right.
$$

The following set of boundary conditions along the edges of the beam is considered:

$$
\begin{aligned}
\tilde{M}_{, x}(0)-M_{, x}(0)-V(0)+F_{z} & =0 \text { and } \widetilde{M}_{, x}(L)-M_{, x}(L)-V(L)+F_{z}=0 \\
M(0)+\widetilde{M}(0) & =0 \text { and } M(L)+\widetilde{M}(L)=0,
\end{aligned}
$$




\section{and $\triangle \mathrm{CCEPTE} \widetilde{\mathrm{M}}(0)=0$ and $\widetilde{\mathrm{M}}(\mathrm{L})=0$}

Substituting Eq. (10) into the governing equations Eq. (12), enables one to obtain a system of two differential equations associated with the present field displacement $\left(w, \gamma_{x z}^{0}\right)$ for the beam:

$$
\left\{\begin{array}{l}
-\mathrm{c}_{2} \mathrm{w}_{, \mathrm{xxx}}+\mathrm{c}_{3} \gamma_{\mathrm{xz}, \mathrm{xx}}^{0}-\mathrm{c}_{4} \gamma_{\mathrm{xz}}^{0}=0 \\
\left(\mathrm{c}_{2}-\mathrm{c}_{1}\right) \mathrm{w}_{, \mathrm{xxxx}}+\left(\mathrm{c}_{2}-\mathrm{c}_{3}\right) \gamma_{\mathrm{xz}, \mathrm{xxx}}^{0}+\mathrm{c}_{4} \gamma_{\mathrm{xz}, \mathrm{x}}^{0}+\mathrm{q}=0
\end{array}\right.
$$

Integrating the second equation of system (14) leads to the following system:

$$
\left\{\begin{array}{l}
-\mathrm{c}_{2} \mathrm{w}_{, \mathrm{xxx}}+\mathrm{c}_{3} \gamma_{\mathrm{xz}, \mathrm{xx}}^{0}-\mathrm{c}_{4} \gamma_{\mathrm{xz}}^{0}=0 \\
\left(\mathrm{c}_{2}-\mathrm{c}_{1}\right) \mathrm{w}_{, \mathrm{xxx}}+\left(\mathrm{c}_{2}-\mathrm{c}_{3}\right) \gamma_{\mathrm{xz}, \mathrm{xx}}^{0}+\mathrm{c}_{4} \gamma_{\mathrm{xz}}^{0}+\mathrm{qx}=\mathrm{K}_{1}
\end{array}\right.
$$

Where $\mathrm{K}_{1}$ is an integration constant. Through a simple combination of the above equations, the following differential equation, where $\gamma_{\mathrm{xz}}^{0}$ is unknown, is obtained.

$$
\gamma_{\mathrm{xz}, \mathrm{xx}}^{0}(\mathrm{x})-\frac{\mathrm{c}_{1} \mathrm{c}_{4}}{\mathrm{c}_{3} \mathrm{c}_{1}-\mathrm{c}_{2}{ }^{2}} \gamma_{\mathrm{xz}}^{0}(\mathrm{x})=\frac{\mathrm{c}_{2}}{\mathrm{c}_{3} \mathrm{c}_{1}-\mathrm{c}_{2}^{2}}\left(\mathrm{qx}-\mathrm{K}_{1}\right)
$$

The differential equation Eq. (16) can be rewritten as follows:

$$
\gamma_{\mathrm{xz}, \mathrm{xx}}^{0}(\mathrm{x})-\omega_{\Phi}^{2} \gamma_{\mathrm{xz}}^{0}(\mathrm{x})=\frac{\mathrm{c}_{2}}{\mathrm{c}_{3} \mathrm{c}_{1}-\mathrm{c}_{2}^{2}}\left(\mathrm{qx}-\mathrm{K}_{1}\right)
$$

Where $\omega_{\Phi}$ is a scalar that depends on $\Phi(\mathrm{z})$

$$
\omega_{\Phi}=\sqrt{\frac{c_{1} c_{4}}{c_{3} c_{1}-c_{2}^{2}}}
$$

The parameter $\omega_{\Phi}$ is a constant which characterizes the decay length of the higher-order effect caused by a warping restraint or shear gradient. The solution of Eq. (17) depends on the sign of the term $\omega_{\Phi}$.

$$
\left[\int_{\mathrm{S}} \overline{\mathrm{Q}}_{11} \mathrm{z}^{2} \mathrm{dS}\right] \times\left[\int_{\mathrm{S}} \overline{\mathrm{Q}}_{11}[\Phi(\mathrm{z})]^{2} \mathrm{dS}\right]-\left[\int_{\mathrm{S}} \overline{\mathrm{Q}}_{11} \mathrm{z}[\Phi(\mathrm{z})] \mathrm{dS}\right]^{2}>0
$$

This inequality is necessarily checked thanks to the Cauchy-Schwarz inequality. A similar reasoning has been followed by Dufort et al. [3,35], Mechab and Challamel [20,24] to determine the sign of the elastic constituents for the integration process. Hence, the energy functional is positive definite at the global scale associated to some convexity arguments of the energy functional.

The solution of the differential equation Eq. (17) is written as

$$
\gamma_{\mathrm{xz}}^{0}(\mathrm{x})=\frac{\mathrm{c}_{2}}{\mathrm{c}_{1} \mathrm{c}_{4}}\left(\mathrm{~K}_{1}-\mathrm{qx}\right)+\beta \cosh \left(\omega_{\Phi} \mathrm{x}\right)+\alpha \sinh \left(\omega_{\Phi} \mathrm{x}\right)
$$


Where $\alpha, \beta$ and $\mathrm{K}_{1}$ are the three constants to be determined from the boundary conditions.

Substituting Eq. (20) into Eq. (14a) and (2), the expression of $\mathrm{w}(\mathrm{x})$ and $\phi^{0}(\mathrm{x})$ can be written as:

$$
\begin{aligned}
\mathrm{w}(\mathrm{x})=\frac{\mathrm{c}_{2}}{\mathrm{c}_{1}} & \frac{1}{\omega_{\Phi}}\left[\alpha \cosh \left(\omega_{\Phi} \mathrm{x}\right)+\beta \sinh \left(\omega_{\Phi} \mathrm{x}\right)\right]+\frac{\mathrm{q}}{\mathrm{c}_{1}} \frac{\mathrm{x}^{4}}{24}-\frac{\mathrm{K}_{1}}{\mathrm{c}_{1}} \frac{\mathrm{x}^{3}}{6}+\mathrm{K}_{2} \frac{\mathrm{x}^{2}}{2}+\mathrm{K}_{3} \mathrm{x}+\mathrm{K}_{4} \\
\phi^{0}(\mathrm{x})= & -\left(1-\frac{\mathrm{c}_{2}}{\mathrm{c}_{1}}\right)\left[\beta \cosh \left(\omega_{\Phi} \mathrm{x}\right)+\alpha \sinh \left(\omega_{\Phi} \mathrm{x}\right)\right]+\frac{\mathrm{q}}{\mathrm{c}_{1}} \frac{\mathrm{x}^{3}}{6}-\frac{\mathrm{K}_{1}}{\mathrm{c}_{1}} \frac{\mathrm{x}^{2}}{2}+\mathrm{K}_{2} \mathrm{x}+\mathrm{K}_{3} \\
& -\frac{\mathrm{c}_{2}}{\mathrm{c}_{1} \mathrm{c}_{4}}\left(\mathrm{~K}_{1}-\mathrm{qx}\right)
\end{aligned}
$$

Where $\mathrm{K}_{1}, \mathrm{~K}_{2}, \mathrm{~K}_{3}, \mathrm{~K}_{4}$ are three additional constants to be determined. The six constants $\alpha, \beta$ and $\mathrm{K}_{\mathrm{i}}$ are obtained from the boundary conditions written both in terms of displacements (Eq. (13)). They lead to the six following expressions:

$$
\begin{gathered}
\mathrm{K}_{1}=\frac{\mathrm{F}_{\mathrm{z}}}{2}+\frac{\mathrm{q}}{2}, \mathrm{~K}_{2}=-\frac{\mathrm{qc}_{2}{ }^{2}}{\mathrm{c}_{1}{ }^{2} \mathrm{c}_{4}}, \mathrm{~K}_{3}=\frac{\left(12 \mathrm{c}_{2}^{2} \mathrm{~L}+\mathrm{c}_{1} \mathrm{c}_{4} \mathrm{~L}^{3}\right)}{24 \mathrm{c}_{1}{ }^{2} \mathrm{c}_{4}} \mathrm{q}+\frac{\left(8 \mathrm{c}_{2}{ }^{2}+\mathrm{c}_{1} \mathrm{c}_{4} \mathrm{~L}^{2}\right)}{16 \mathrm{c}_{1} \mathrm{c}_{4}} \mathrm{~F}_{\mathrm{z}} \\
\mathrm{K}_{4}=-\frac{\mathrm{qc}_{2}{ }^{2}}{\omega_{\Phi}{ }^{2} \mathrm{c}_{1}}, \alpha=-\frac{\mathrm{qC} \mathrm{c}_{2} \sinh \left(\frac{\omega_{\Phi} \mathrm{L}}{2}\right)}{\omega_{\Phi} \mathrm{C}_{1} \mathrm{C}_{4}}, \beta=-\frac{\mathrm{F}_{\mathrm{z}} \mathrm{c}_{2}}{\omega_{\Phi} \mathrm{c}_{1} \mathrm{c}_{4} \cosh \left(\frac{\omega_{\Phi} \mathrm{L}}{2}\right)}-\frac{\omega_{1} \mathrm{~L}}{2 \mathrm{c}_{1} \cosh \left(\frac{\omega_{\Phi}}{2}\right)}
\end{gathered}
$$

\section{Simply supported beam with uniformly and central concentrated load}

\subsection{Uniformly distributed load $q\left(F_{z}=0\right)$}

A simply supported beam with a rectangular cross-section $(\mathrm{b} \times \mathrm{h})$ is subjected to a uniformly distributed load (UDL) q over the span $L$ at surface $z=-h / 2$ in the downward $z$-direction (Fig. 2). The origin of the beam is taken at the left end support, i.e. at $\mathrm{x}=0$.

The boundary conditions, $\mathrm{w}_{, \mathrm{x}}=0$ and $\phi^{0}=0$ at $\mathrm{x}=\mathrm{L} / 2$ is used for the condition of symmetry of deformation. The general solution for the expressions of $\mathrm{w}(\mathrm{x})$ and $\phi^{0}(\mathrm{x})$ are obtained as follows: 


$$
\begin{aligned}
& \mathrm{w}(\mathrm{x})=\mathrm{q}\left(\frac{\left(\frac{\mathrm{x}^{4}}{24}-\frac{\mathrm{Lx}}{12}+\frac{\mathrm{xL}^{3}}{24}\right)}{\mathrm{c}_{1}}+\frac{\mathrm{c}_{2}^{2}}{\mathrm{c}_{1}{ }^{2} \mathrm{c}_{4}}\left(\frac{\mathrm{Lx}}{2}-\frac{\mathrm{x}^{2}}{2}+\frac{\cosh \left(\omega_{\Phi} \mathrm{x}\right)-\frac{\sinh \left(\frac{\omega_{\Phi} \mathrm{L}}{2}\right) \sinh \left(\omega_{\Phi} \mathrm{x}\right)}{\cosh \left(\frac{\omega_{\Phi} \mathrm{L}}{2}\right)}-1}{\omega_{\Phi}{ }^{2}}\right)\right) \\
& \gamma_{x z}^{0}(x)=\frac{c_{2}}{c_{1} c_{4}}\left(\frac{L}{2}-x+\frac{\sinh \left(\omega_{\Phi} x\right)-\frac{\sinh \left(\frac{\omega_{\Phi} L}{2}\right) \cosh \left(\omega_{\Phi} x\right)}{\cosh \left(\frac{\omega_{\Phi} L}{2}\right)}}{\omega_{\Phi}}\right) q
\end{aligned}
$$

The displacements and stresses (static bending response) of the beam can now be obtained using this solution. The results of simply supported beam subjected to UDL, for maximum non-dimensional transverse displacement, normal bending stress and transverse shear stress are presented in Table 2 .

\subsection{Central concentrated load $F_{z}(\mathrm{q}=0)$}

A simply supported beam with rectangular cross-section $(\mathrm{b} \times \mathrm{h})$ is subjected to concentrated load $F_{z}$ at mid span (Fig. 3), i.e. at $\mathrm{x}=\mathrm{L} / 2$ at surface $\mathrm{z}=-\mathrm{h} / 2$. The origin beam is taken at the left end support, i.e. at $\mathrm{x}=0$. The boundary conditions associated with simply supported beam can be obtained from Eqs. (28) and (32).

Thus, the general solutions for $\mathrm{w}(\mathrm{x})$ and $\gamma_{\mathrm{xz}}^{0}(\mathrm{x})$ are obtained as follows.

$$
\begin{array}{r}
\mathrm{w}(\mathrm{x})=\frac{\mathrm{F}_{\mathrm{z}} \mathrm{L}^{2}}{48 \mathrm{c}_{1}}\left(\left(-\mathrm{x}\left(4\left(\frac{\mathrm{x}}{\mathrm{L}}\right)^{2}+3\right)\right)+\frac{12 \mathrm{c}_{2}^{2}}{\mathrm{c}_{1} \mathrm{c}_{4} \mathrm{~L}^{2}}\left(\mathrm{x}-\frac{1}{\omega_{\Phi}} \frac{\sinh \left(\omega_{\Phi} \mathrm{x}\right)}{\cosh \left(\frac{1}{2} \omega_{\Phi} \mathrm{L}\right)}\right)\right) \\
\gamma_{\mathrm{xz}}^{0}(\mathrm{x})=\frac{\mathrm{F}_{\mathrm{z}} \mathrm{c}_{2}}{2 \mathrm{c}_{1} \mathrm{c}_{4}}\left(1-\frac{\cosh \left(\omega_{\Phi} \mathrm{x}\right)}{\cosh \left(\frac{1}{2} \omega_{\Phi} \mathrm{L}\right)}\right)
\end{array}
$$


The results of a simply supported beam subjected to a concentrated load, in terms of the maximum non-dimensional transverse displacement, the normal stress and the transverse shear stress are presented in Table 3 . The values of the axial stress are presented at $x=L / 2$ from the left end support.

\section{Equilibrium equations}

\subsection{Study of the equilibrium equation}

The purpose of this study is to determine a condition on the warping function for which the equilibrium equation Eq. (28) is perfectly satisfied. The approach presented in this paper is based on kinematics conditions. The objective now is to examine the conditions for which the equilibrium equations are checked. The first equilibrium equation enables one to propose a new warping function different from the traditional functions.

$$
\frac{\partial \sigma_{x x}}{\partial x}+\frac{\partial \tau_{x z}}{\partial z}=0
$$

Eqs. (24) and (25) can be rewritten in a clearer way to identify the role of each of the terms of the displacement field, firstly, by introducing the term derived from the classical beam theory, which represents the contribution of the bending [35].

$$
\begin{aligned}
& \mathrm{w}(\mathrm{x})=\frac{\mathrm{qL}^{4}}{24 \mathrm{c}_{1}}\left(\Theta(\mathrm{x})+\mathrm{S}_{\Phi} \psi(\mathrm{x})\right) \\
& \gamma_{\mathrm{xz}}^{0}(\mathrm{x})=\frac{\mathrm{S}_{\Phi} \psi_{, \mathrm{x}}(\mathrm{x}) \mathrm{qL}^{4}}{24 \mathrm{c}_{2}}
\end{aligned}
$$

where

$$
\begin{aligned}
& \Theta(x)=\left(\frac{x}{L}\right)^{4}-2\left(\frac{x}{L}\right)^{3}+\left(\frac{x}{L}\right) \\
& \psi(x)=\frac{L x}{2}-\frac{x^{2}}{2}+\frac{\cosh \left(\omega_{\Phi} x\right)-\frac{\sinh \left(\frac{\omega_{\Phi} L}{2}\right) \sinh \left(\omega_{\Phi} \mathrm{x}\right)}{\cosh \left(\frac{\omega_{\Phi} L}{2}\right)}-1}{\omega_{\Phi}^{2}} \\
& S_{\Phi}=\frac{24 c_{2}^{2}}{c_{1} c_{4} L^{4}}
\end{aligned}
$$

Substituting Eqs. (5), (6) and Eq. (29) into Eq. (28) gives:

$$
\Phi, \mathrm{zz}(\mathrm{z})+\frac{\overline{\mathrm{Q}}_{11}}{\overline{\mathrm{Q}}_{55}} \frac{\psi_{, \mathrm{xxx}}(\mathrm{x})}{\psi_{, \mathrm{x}}(\mathrm{x})} \Phi(\mathrm{z})=\mathrm{z} \frac{\overline{\mathrm{Q}}_{11}}{\overline{\mathrm{Q}}_{55}} \frac{\mathrm{L}^{4} \mathrm{c}_{4}}{24 \mathrm{c}_{2} \psi_{, 1}\left(\mathrm{x}_{1}\right)}\left(\Theta,,_{\mathrm{xxx}}(\mathrm{x})+\mathrm{S}_{\Phi} \psi,{ }_{\mathrm{xxx}}(\mathrm{x})\right)
$$


The solution of this equation enables one to determine a new warping function $\Phi(z)$ satisfying the equilibrium equation of stress. Eq. (31) can be also put in the following compact form:

$$
\Phi,{ }_{\mathrm{zz}}(\mathrm{z})-\Phi(\mathrm{z}) \Omega_{\Phi}{ }^{2}(\mathrm{x})=\mathrm{zC}_{\Phi}(\mathrm{x})
$$

with

$$
\Omega_{\Phi}(\mathrm{x})=\sqrt{-\frac{\mathrm{E}_{11} \psi_{, \mathrm{xxx}}(\mathrm{x})}{\mathrm{G}_{13} \psi_{, \mathrm{x}}(\mathrm{x})}}
$$

According to Eq. (30), the terms $\psi_{, \mathrm{x}}(\mathrm{x}), \psi_{\text {, xxx }}(\mathrm{x})$ are respectively the first and third derivative of $\psi(\mathrm{x})$ according to $\mathrm{x}$.

$$
\psi_{, \mathrm{xxx}}(\mathrm{x})=\omega_{\Phi}\left(\sinh \left(\omega_{\Phi} \mathrm{x}\right)-\frac{\sinh \left(\frac{\omega_{\Phi} \mathrm{L}}{2}\right) \cosh \left(\omega_{\Phi} \mathrm{x}\right)}{\cosh \left(\frac{\omega_{\Phi} \mathrm{L}}{2}\right)}\right)
$$

$\psi$, $_{\mathrm{xxx}}(\mathrm{x})$ is negative. Eq. (34) can be rewritten in the reduced form:

$$
\psi_{, \mathrm{xxx}}(\mathrm{x})=-\omega_{\Phi} \frac{\sinh \left(\omega_{\Phi}\left(\frac{\mathrm{L}}{2}-\mathrm{x}\right)\right)}{\cosh \left(\frac{\omega_{\Phi} \mathrm{L}}{2}\right)}<0
$$

In the same way for $\psi_{, \mathrm{x}}(\mathrm{x})$, it is obtained:

$$
\psi_{, \mathrm{x}}(\mathrm{x})=-\mathrm{x}+\frac{\mathrm{L}}{2}-\frac{\sinh \left(\omega_{\Phi}\left(\frac{\mathrm{L}}{2}-\mathrm{x}\right)\right)}{\omega_{\Phi} \cosh \left(\frac{\omega_{\Phi} \mathrm{L}}{2}\right)}
$$

The term $\frac{\sinh \left(\omega_{\Phi}\left(\frac{L}{2}-x\right)\right)}{\omega_{\Phi} \cosh \left(\frac{\omega_{\Phi} L}{2}\right)}$ is very small, consequently it does not have an influence on the evolution of the sign of $\psi_{, \mathrm{x}}(\mathrm{x})$ since $0 \leq \mathrm{x} \leq \mathrm{L} / 2$ that is to say $-\mathrm{x}+\mathrm{L} / 2 \geq 0$ thus the term under the square of $\Omega_{\Phi}(\mathrm{x})$ is positive whatever $x$ and the odd function $\Phi(z)$.

The second term of Eq. (32) is written in the following form:

$$
\mathrm{C}_{\Phi}(\mathrm{x})=\frac{\overline{\mathrm{Q}}_{11}}{\overline{\mathrm{Q}}_{55}} \frac{\mathrm{L}^{4} \mathrm{c}_{4}}{24 \mathrm{c}_{2} \psi_{, \mathrm{x}}(\mathrm{x})}\left(\Theta,,_{\mathrm{xxx}}(\mathrm{x})+\mathrm{S}_{\mathrm{m}} \psi,{ }_{\mathrm{xxx}}(\mathrm{x})\right)
$$


$\mathrm{z}$. The equation utilizes also the terms $\mathrm{c}_{1}, \mathrm{c}_{2}, \mathrm{c}_{3}$, and $\mathrm{c}_{4}$ which, as seen previously, depend on the form of $\Phi(\mathrm{z})$. Taking into account the complexity of this equation, the idea for the following continuation of calculation is to postulate an initial form for $\Phi(\mathrm{z})$, noted $\Phi_{0}(\mathrm{z})$ and a constant value for $x$ between 0 and $\mathrm{L} / 2$. The coefficients $\Omega_{\Phi 0}(\mathrm{x}), \mathrm{C}_{\Phi 0}(\mathrm{x})$ can be calculated and thus the differential equation can be solved. The new form of $\Phi$, noted $\Phi(\mathrm{z})_{\mid \mathrm{x}}$, is then used in an iterative calculation until obtaining a stable expression considered as a solution in variable $x$.

The resolution of the differential Eq. (32), where $\Omega_{\Phi 0}{ }^{2}(\mathrm{x})$ and $\mathrm{C}_{\Phi 0}(\mathrm{x})$ are constant needs first a particular solution noted $\Phi_{\mathrm{p}}(\mathrm{z})_{\mid \mathrm{x}}$ of the complete equation with constant coefficients for a given $x$, and then the general solution of the noted homogeneous equation $\Phi_{h}(z)_{\mid x}[35]$; such as :

$$
\left\{\begin{array}{l}
\Phi(\mathrm{z})_{\mid \mathrm{x}}=\Phi_{\mathrm{h}}(\mathrm{z})_{\mid \mathrm{x}}+\Phi_{\mathrm{p}}(\mathrm{z})_{\mid \mathrm{x}}=-\frac{\mathrm{C}_{\Phi}(\mathrm{x})}{\Omega_{\Phi}^{2}(\mathrm{x})} \mathrm{z}, \quad \forall \mathrm{x} \in\left[0, \frac{\mathrm{L}}{2}[\right. \\
\Phi_{\mathrm{h}, \mathrm{zz}}(\mathrm{z})_{\mid \mathrm{x}}-\Omega_{\Phi}{ }^{2}(\mathrm{x}) \Phi_{\mathrm{h}}(\mathrm{z})_{\mid \mathrm{x}}=0, \quad \forall \mathrm{x} \in\left[0, \frac{\mathrm{L}}{2}[\right.
\end{array}\right.
$$

$\Phi(z)_{\mid x}$ represents the expression of the warping function determined in $x$. The solution is:

$$
\Phi(\mathrm{z})_{\mid \mathrm{x}}=-\frac{\mathrm{C}_{\Phi}(\mathrm{x})}{\Omega_{\Phi}{ }^{2}(\mathrm{x})} \mathrm{z}+\alpha(\mathrm{x}) \sinh \left(\Omega_{\Phi}(\mathrm{x}) \mathrm{z}\right)+\beta(\mathrm{x}) \cosh \left(\Omega_{\Phi}(\mathrm{x}) \mathrm{z}\right)
$$

The determination of the constants $\alpha(\mathrm{x})$ and $\beta(\mathrm{x})$ is carried out starting from the following relations relating on the distribution of the stress in the thickness of the beam, considering also the symmetry of the function $\Phi(\mathrm{z})_{\mid \mathrm{x}}$ which is odd:

$$
\left\{\begin{array} { l } 
{ \Phi ( 0 ) _ { | \mathrm { x } } = 0 , \quad \forall \mathrm { x } \in [ 0 , \frac { \mathrm { L } } { 2 } [ } \\
{ \Phi _ { , \mathrm { z } } ( \frac { \mathrm { h } } { 2 } ) _ { | \mathrm { x } } = \Phi _ { , \mathrm { z } } ( - \frac { \mathrm { h } } { 2 } ) _ { | \mathrm { x } } = 0 , \quad \forall \mathrm { x } \in [ 0 , \frac { \mathrm { L } } { 2 } [ }
\end{array} \text { that leads to } \left\{\begin{array}{l}
\beta(\mathrm{x})=0 \\
\alpha(\mathrm{x})=\frac{\mathrm{C}_{\Phi}(\mathrm{x})}{\Omega_{\Phi}{ }^{3}(\mathrm{x})} \frac{1}{\cosh \left(\frac{\mathrm{h}}{2} \Omega_{\Phi}(\mathrm{x})\right)}
\end{array}\right.\right.
$$

The general solution has the following form:

$$
\Phi(\mathrm{z})_{\mid \mathrm{x}}=\phi_{2}(\mathrm{x}) \mathrm{z}+\phi_{1}(\mathrm{x}) \sinh \left(\Omega_{\Phi}(\mathrm{x}) \mathrm{z}\right)
$$

With

$$
\phi_{1}(\mathrm{x})=\frac{\mathrm{C}_{\Phi}(\mathrm{x})}{\Omega_{\Phi}^{3}(\mathrm{x})} \frac{1}{\cosh \left(\frac{\mathrm{h}}{2} \Omega_{\Phi}(\mathrm{x})\right)}, \phi_{2}(\mathrm{x})=-\frac{\mathrm{C}_{\Phi}(\mathrm{x})}{\Omega_{\Phi}{ }^{2}(\mathrm{x})}
$$


paper. The presence of the hyperbolic form in this formulation enables one to obtain the warping of the initial section found by the cubic form of Reddy (PSDBT) or the sine form of Touratier (SSDBT).

This diagram is similar to the one used by Dufort [35] with a stabilization process which is the main novelty of the present work.

Here, $\left|X_{i}-X_{i-1}\right|$ represents the variation of the coefficients

$$
\left|\mathrm{X}_{\mathrm{i}}-\mathrm{X}_{\mathrm{i}-1}\right|=\left\{\begin{array}{l}
\left|\Omega_{(\mathrm{i})}(\mathrm{x})-\Omega_{(\mathrm{i}-\mathrm{i})}(\mathrm{x})\right| \\
\left|\phi_{1(\mathrm{i})}(\mathrm{x})-\phi_{1(\mathrm{i}-\mathrm{i})}(\mathrm{x})\right| \leq \xi=0.5 \cdot 10^{-3} \\
\left|\phi_{2(\mathrm{i})}(\mathrm{x})-\phi_{2(\mathrm{i}-\mathrm{i})}(\mathrm{x})\right|
\end{array}\right.
$$

\subsection{Function of warping}

According to Dufort [35] in a three - point bending configuration, the warping function depends on the material proprieties and on the geometrical characteristics of the beam. The new shape function developed in the present work by stabilization of Dufort function for a uniform distributed load depends on the thickness of the beam. According to the analytical development, the function will depend on the coefficients $\Omega_{(\mathrm{i}-1)}(\mathrm{x}), \phi_{1(\mathrm{i}-1)}(\mathrm{x})$ and $\phi_{2(\mathrm{i}-1)}(\mathrm{x})$ and the length of the beam. Finally Eq.39 which is written in a stabilized form depends only on the thickness of the beam. Furthermore, according to Aydogdu and Soldatos models [18, 39], $\Omega(\mathrm{x})$ is equal to $1 / \mathrm{h}$ and $\pi / \mathrm{h}$ for Touratier [14].

According to equation Eq. (5b), the transverse deformation depends on the derivate of the warping function. It is clear that the Reddy function (PSDBT), the Touratier function (SSDBT) and even the other forms proposed in the literature, lead to $\Phi^{\prime}(0)=1$. The same results are obtained if the terms of the new derived function are superimposed with a Taylor series transformations:

$$
\Phi^{\prime}(\mathrm{z})=\left(1-4 \mathrm{z}^{2} / \mathrm{h}^{2}\right)_{\text {Reddy }}=\left(-\frac{\mathrm{C}(\mathrm{x})}{\Omega^{2}(\mathrm{x})}+\frac{\mathrm{C}(\mathrm{x})}{\Omega^{2}(\mathrm{x}) \cosh \left(\frac{\mathrm{h}}{2} \Omega(\mathrm{x})\right)}+\frac{\mathrm{C}(\mathrm{x})}{2 \cosh \left(\frac{\mathrm{h}}{2} \Omega(\mathrm{x})\right)} \mathrm{z}^{2}\right)_{\text {New }}
$$


By replacing the expression of $\Omega(\mathrm{x})=\frac{\pi}{\mathrm{h}}$ or $\frac{1}{\mathrm{~h}}$ into Eq. (44), we obtain:

$\left.\Phi^{\prime}(0)\right|_{\text {Reddy }}=\left.\Phi^{\prime}(0)\right|_{\text {New }} \Rightarrow-\frac{\mathrm{C}(\mathrm{x})}{\Omega^{2}(\mathrm{x})}+\frac{\mathrm{C}(\mathrm{x})}{\Omega^{2}(\mathrm{x}) \cosh \left(\frac{\mathrm{h}}{2} \Omega(\mathrm{x})\right)}=1 \Rightarrow\left\{\begin{array}{l}\frac{\pi}{\mathrm{h}} \\ \frac{1}{\mathrm{~h}}\end{array} \Rightarrow \mathrm{C}(\mathrm{x})=\left\{\begin{array}{l}-\frac{\pi^{2} \cosh \left(\frac{\pi}{2}\right)}{\mathrm{h}^{2}\left(\cosh \left(\frac{\pi}{2}\right)-1\right)} \\ -\frac{\cosh \left(\frac{1}{2}\right)}{\mathrm{h}^{2}\left(\cosh \left(\frac{1}{2}\right)-1\right)}\end{array}\right.\right.$

Therefore, an equation of warping is obtained in the hyperbolic form which depends only on the geometrical properties and which satisfies the conditions of zero of the deformations at the edges. The equation is written in the following form:

$$
\Phi(\mathrm{z})=\left\{\begin{array}{l}
\frac{\cosh \left(\frac{\pi}{2}\right)}{\left(\cosh \left(\frac{\pi}{2}\right)-1\right)} \mathrm{z}-\frac{\mathrm{h}}{\pi} \frac{\sinh \left(\frac{\pi}{\mathrm{h}} \mathrm{z}\right)}{\left(\cosh \left(\frac{\pi}{2}\right)-1\right)} \\
\frac{\cosh \left(\frac{1}{2}\right)}{\left(\cosh \left(\frac{1}{2}\right)-1\right)} \mathrm{z}-\mathrm{h} \frac{\sinh \left(\frac{\mathrm{z}}{\mathrm{h}}\right)}{\left(\cosh \left(\frac{1}{2}\right)-1\right)}
\end{array}\right.
$$

\subsection{Comparison and discussion}

The validation of the present methodology is performed by means of comparisons with various other results:

- Results of analytical studies available in the international literature, with various other warping functions

- Finite Element Calculations performed by the authors

- Experimental results of Dufort [3,36]

For the two first points of this part (analytical studies and FE calculations), a graphite composite $\mathrm{T} 300 / 934$ is considered with the following mechanical properties: $\mathrm{E}_{11}=140 \mathrm{GPa}, \mathrm{E}_{11} / \mathrm{G}_{13}=40, \mathrm{v}=0.3$. Furthermore, the beam is assumed to have a section $\mathrm{L} / \mathrm{h}=5$ with $\mathrm{L}=20 \mathrm{~mm}[3]$.

Figs 5, 6 and 7 show the variations of the iterative warping functions $\phi_{1}, \phi_{2}$ and $\Omega$ in function of the number of iterations for a uniform distributed load and for two different values 
of $\mathrm{x}: \mathrm{x}=0$ and $\mathrm{x}=6$. All these functions were found to converge at the eighth iteration. $\phi_{1}$ tends to 0 while $\phi_{2}$ tends to a constant value equal to 0.84709 which approximates the Timoshenko shear correction factor $\kappa=5 / 6$.

Fig. 8 shows the variation of the warping functions through the thickness of the beam for different theories. The present iterative model is in good agreement with the model of Touratier (SSDBT) and Reddy (PSDBT).

The finite element calculations were performed using FEM software ABAQUS/standard (static calculation). The geometrical properties are those presented just above, the mechanical properties are considered isotropic: a Young's modulus of $140 \mathrm{GPa}$ and a Poisson's ratio of 0.3 are considered. Besides, the beam is subjected to a uniform distributed load $\mathrm{q}=250 \mathrm{kN} / \mathrm{m}$. In this section, the used finite elements are CPS8R: 2D deformable 8-node biquadratic plane stress quadrilateral isoparametric finite elements. They are used to discretize the beam geometry (Fig. 9). The optimal mesh has been deduced from a sensitivity analysis on the fineness of the mesh. A total of 1282 elements and 4039 nodes are used.

Fig. 10, 11 and 12 represent the variation of the deflection, of the longitudinal displacement, and of the transverse shear stress respectively. It is found that all enriched models converge to the variations found by the Finite Element Method: as for example, the transverse stress tends to zero in the upper and lower free edges and reaches its maximal value in the middle plane.

Fig. 13, 14 and 15 represent the variation of the deflection, the longitudinal displacement and the transverse deformation respectively, in function of the dimensions of the length and the thickness of the orthotropic beam subjected to a three-point bending. It is found that after stabilization of the iterative function all the various models converge to the same values.

Fig. 16 and 17 present comparisons of the variation of the longitudinal displacement and the transverse deformation respectively, obtained by means of the present analytical study and the experimental study led by Dufort $[3,36]$ based on an optical technique, developed by Surrel [37], to capture the displacement fields on laminated beams subjected to three points bending. The characteristics of carbon/epoxy used to compare analytical and experimental results are: $\mathrm{E}_{11}=115 \mathrm{GPa}, \mathrm{G}_{13}=3 \mathrm{GPa}$. The beam is assumed to have a section such as $\mathrm{b}=30.28 \mathrm{~mm}, \mathrm{~L} / \mathrm{h}=6.16$ with $\mathrm{L}=125 \mathrm{~mm}$, a load $\mathrm{F}_{\mathrm{z}}=22 \mathrm{kN}$ is applied at mid-span $[3,36]$. As it can be seen from Fig. 16 and 17 the predicted theoretical results agree with the experimental results presented by Dufort. 


\section{Conclusion}

In this paper, a general solution is firstly proposed to study the bending of simply supported laminated beams under mechanical loading and taking into account the transverse deformation.

Secondly, based on the equations of displacements developed in the first part and the stress equilibrium conditions, a new warping function is developed. This function depends only on the thickness of the beam. Its evolution approaches that of the Reddy function (PSDBT) and Touratier function (SSDBT) and satisfies the conditions of zero transverse stress in the upper and lower surfaces of the beam. This new formulation is not limited to static bending of beams, it can be extended to study vibrations and also to plates. 


\section{References}

ACCEPTED MANUSCRIPT

[1] Reddy, J.N., Mechanics of Laminated Composite Plates and Shells, CRC press, New York, 2003.

[2] Zenkour, A.M., Analytical solution for bending of cross-ply laminated plates under thermo-mechanical loading, Composite Structures 65 (2004) 367-379.

[3] Dufort, L., Drapier, S., Grediac, M., Closed from solution for the cross section warping in short beams under three point bending, Composite structures 52(2) (2001) 233-246.

[4] Timoshenko, S. P., On the correction for shear of the differential equation for transverse vibrations of prismatic bars, Philosophical Magazine, Series 6, pp. 742-746.

[5] Timoshenko, S.P., On the transverse vibration of bars with uniform cross-section, Philosophical Magazine, 43 (1922) 125-131.

[6] Vlasov BF. Ob uravnieniah izgiba plastinok (On equations of bending of plates). Doklady Akademii Nauk Azerbeijanskoi SSR 3 (1957) 955-9.

[7] Levinson, M., A new rectangular beam theory, J. Sound Vib. 74(1), 81-87.

[8] Reddy, JN., A simple higher-order theory for laminated composite plates. J Appl Mech 51 (1984) 745-752.

[9] Bickford, W. B. , A consistent higher order beam theory, Dev. Theor. Appl. Mech. SECTAM 11, 137-150.

[10] Krishna Murty, A. V., Towards a consistent beam theory, AIAA J. 22(6), 811-816.

[11] Baluch, M. H., Azad, A. K. and Khidir, M. A., Technical theory of beams with normal strain, ASCE, J. Eng. Mech. 110(8), 1233-1237.

[12] Kant, T. and Gupta, A, A finite element model for a higher order shear deformable beam theory, J. Sound Vib. 125(2), 19 Bhimaraddi, A. and Chandrashekhara, K., Observations on higher order beam theory, ASCE, J. Aerosp. Eng. 6(4), 408-413.

[14] Touratier, M., An efficient standard plate theory, International Journal of Engineering Sciences 29 (8) (1991) 901-916.

[15] Mechab, B., Mechab, I., Benaissa, S., Analysis of thick orthotropic laminated composite plates based on higher order shear deformation theory by the new function under thermomechanical loading.Composites: Part B 43 (2012) 1453-1458.

[16] Ghugal, Y. M. and Shimpi, R. P., A trigonometric shear deformation theory for flexure and free vibration of isotropic thick beams, Structural Engineering Convention, SEC-2000, IIT Bombay, India, 255-263.

[17] Karama, M., Afaq, K.S., Mistou, S., Mechanical behaviour of laminated composite beam by the new multi-layered laminated composite structures model with transverse shear stress continuity, Int. J. Solids Structures 40 (2003) 1525-1546. 
[18] Aydogdu, M., Vibration analysis of cross-ply laminated beams with general boundary

conditions by Ritz method, International Journal of Mechanical Sciences 47 (2005) 17401755.

[19] Ghugal., Y. M and Rajneesh, S., Hyperbolic shear deformation theory for flexure and vibration of thick isotropic beams, International Journal of Computational Methods 6 (4) (2009) 585-60.

[20] Mechab, I., Etude des structures composites en utilisant les théories d'ordre élevé sous chargement thermomécanique, (in French), PhD Thesis, University of Sidi Bel Abbes, Laboratoire Des Matériaux Et Hydrologie LM\&H, May 2009, 2009.

[21] Mechab, I., Tounsi, A., Benatta, M.A., Adda Bedia, E.A., Deformation of short composite beam using refined theories, J. Math. Anal. Appl. 346 (2008) 468-479.

[22] El Meiche, N., Tounsi, A., Ziane, N., Mechab, I. and Adda Bedia E.A., A new hyperbolic shear deformation theory for buckling and vibration of functionally graded sandwich plate, Int. J. Mech. Sc. 53 (2011) 237-247.

[23] Ait Atmane, H., Tounsi, A., Mechab, I. and Adda Bedia, E., Free vibration analysis of functionally graded plates resting on Winkler-Pasternak elastic foundations using a new shear deformation theory, Int. J. Mech. Mater. Design, 6, 2, 113-121, 2010.

[24] Challamel, N., Mechab, I., El Meiche, N., Houari, M.S.A., Ameur, M., Ait Atmane, H. Buckling of generic higher-order shear beam/columns with elastic connections: local and nonlocal formulation, ASCE Journal of Engineering Mechanics 139(8) (2013) 1091-1109.

[25] Mantari, J.L., Oktem, A.S., Guedes Soares, C., Bending and free vibration analysis of isotropic and multilayered plates and shells by using a new accurate higher-order shear deformation theory, Composites: Part B 43 (2012) 3348-3360.

[26] J.L. Mantari, A.S. Oktem, C. Guedes Soares, A new higher order shear deformation theory for sandwich and composite laminated plates, Composites: Part B 43 (2012) 14891499.

[27] Sobhy, M., Buckling and free vibration of exponentially graded sandwich plates resting on elastic foundations under various boundary conditions. Composite Structures 99 (2013) $76-87$.

[28] Vlasov V.Z., Thin-walled elastic beams. Pergamon Press, New York (1961).

[29] Barsoum R.S., Gallagher R.H., Finite element analysis of torsional and torsional-flexural stability problems. International Journal for Numerical Methods in Engineering 2 (1970) 33552. 
[30] Mancusi G., Feo L. Non-linear pre-buckling behavior of shear deformable thin-walled composite beams with open cross-section, Composites Part B: Engineering 47 (2013) 379390.

[31] Feo L., Mancusi G., The influence of the shear deformations on the local stress state of pultruded composite profiles, Mechanics Research Communications 47 (2013) 44-49.

[32] Feo, L., Mancusi, G. Modeling shear deformability of thin-walled composite beams with open cross-section, Mechanics Research Communications 37(3) (2010) 320-325.

[33] Minghini F., Tullini N., Laudiero F., Locking-free finite elements for shear deformable orthotropic thin-walled beams, Int J Numer Meth Eng 72 (2007) 808-834.

[34] Brault R., Étude du comportement mécanique des matériaux composites par corrélation volumique : Application à l'analyse des effets du cisaillement transverse (in French), $\mathrm{PhD}$ Thesis, Institut National Polytechnique de Toulouse (INP Toulouse), 2013.

[35] Dufort. L., Etude de cisaillement transverse dans des poutres stratifiés et sandwich: Aspect théorique et expérimentaux (in French), $\mathrm{PhD}$ Thesis, Blaise Pascal-Clermont II University, 2000.

[36] Dufort, L., Grediac, M., Surrel., Y., Experimental evidence of the cross section warping in short composite beams under three point bending, Composite structures 51 (2000) 37-47.

[37] Surrel, Y., Zhao, B., Simultaneous u-v displacement field measurement with a phaseshifting grid method». In: Pryputniewicz RJ, Stupnicki J, editors. Interferometry '94: Photomechanics, vol. SPIE 2342, 66-75, 1994.

[38] Soldatos KP, Timarci T., A unified formulation of laminated composite, shear deformable, five-degrees-of-freedom cylindrical shell theories. Composite Structures 25 (1993) 165-71.

[39] Soldatos KP. A transverse shear deformation theory for homogeneous monoclinic plates. Acta Mechanica 94(3-4) (1992) 195-220. 
Table 1: Expression of the various coefficients $\mathrm{c}_{\mathrm{i}}$ for polynomial and sinusoidal shear deformation beams theories (PSDBT and SSDBT).

\begin{tabular}{|c|c|c|}
\hline $\mathrm{c}_{\mathrm{i}}$ & $($ PSDBT $) \Phi(\mathrm{z})=\mathrm{z}\left(1-4 \mathrm{z}^{2} / 3 \mathrm{~h}^{2}\right)$ & $($ SSDBT $) \Phi(\mathrm{z})=\mathrm{h} / \pi \sin (\mathrm{z} \pi / \mathrm{h})$ \\
\hline $\mathrm{c}_{1}$ & $\frac{1}{12} \overline{\mathrm{Q}}_{11} \mathrm{bh}^{3}$ & $\frac{1}{12} \overline{\mathrm{Q}}_{11} \mathrm{bh}^{3}$ \\
\hline $\mathrm{c}_{2}$ & $\frac{1}{15} \overline{\mathrm{Q}}_{11} \mathrm{bh}^{3}$ & $\frac{2}{\pi^{3}} \overline{\mathrm{Q}}_{11} \mathrm{bh}^{3}$ \\
\hline $\mathrm{c}_{3}$ & $\frac{17}{315} \overline{\mathrm{Q}}_{11} \mathrm{bh}^{3}$ & $\frac{1}{2 \pi^{2}} \overline{\mathrm{Q}}_{11} \mathrm{bh}^{3}$ \\
\hline $\mathrm{c}_{4}$ & $\frac{8}{15} \overline{\mathrm{Q}}_{55} \mathrm{bh}$ & $\frac{1}{2} \overline{\mathrm{Q}}_{55} \mathrm{bh}$ \\
\hline
\end{tabular}

Table 2. Nondimensional maximum transverse displacement $\left(\overline{\mathrm{w}^{0}}=10 \mathrm{E}_{11} \mathrm{bh}^{3} \mathrm{w}(\mathrm{L} / 2,0) / \mathrm{qL}^{4}\right)$, axial stress $\left(\bar{\sigma}_{\mathrm{x}}=\frac{\mathrm{b}}{\mathrm{q}} \sigma_{\mathrm{xx}}\left(\frac{\mathrm{L}}{2}, \frac{\mathrm{h}}{2}\right)\right)$, and transverse shear stress $\left(\bar{\tau}_{\mathrm{xz}}=\frac{\mathrm{b}}{\mathrm{q}} \tau_{\mathrm{xz}}(0,0)\right)$ for simply supported beam subjected to uniformly distributed load (UDL) for two different aspect ratios $\mathrm{L} / \mathrm{h}[19]$.

\begin{tabular}{|c|l|l|c|c|c|}
\hline $\mathrm{L} / \mathrm{h}$ & theories & Model & $\overline{\mathrm{w}^{0}}$ & $\bar{\sigma}_{\mathrm{x}}$ & $\bar{\tau}_{\mathrm{xz}}$ \\
\hline \multirow{3}{*}{4} & Euler-Bernoulli & CLBT & 1.5625 & 12.0000 & - \\
\cline { 2 - 6 } & Timoshenko $[\mathrm{\kappa}=5 / 6]$ & FSDBT & 1.8062 & 12.0000 & 2.4000 \\
\cline { 2 - 6 } & Reddy & PSDBT & 1.8059 & 13.5600 & 2.9165 \\
\cline { 2 - 6 } & Touratier & SSDBT & 1.8054 & 13.5577 & 3.0006 \\
\hline \multirow{3}{*}{10} & Euler-Bernoulli & CLBT & 1.5625 & 75.0000 & - \\
\cline { 2 - 6 } & Timoshenko [ $\mathrm{K}=5 / 6]$ & FSDBT & 1.6015 & 75.0000 & 6.0000 \\
\cline { 2 - 6 } & Reddy & PSDBT & 1.6015 & 76.5600 & 7.4165 \\
\cline { 2 - 6 } & Touratier & SSDBT & 1.6014 & 76.5577 & 7.6448 \\
\hline
\end{tabular}


Table3. Nondimensional CEPT maximum SCR IP transverse displacement

$\left(\overline{\mathrm{w}^{0}}=10 \mathrm{E}_{11} \mathrm{bh}^{3} \mathrm{w}(\mathrm{L} / 2,0) / \mathrm{F}_{\mathrm{z}} \mathrm{L}^{3}\right)$, axial stress $\left(\bar{\sigma}_{\mathrm{x}}=\mathrm{bh} \sigma_{\mathrm{xx}}(\mathrm{L} / 2, \mathrm{~h} / 2) / \mathrm{F}_{\mathrm{z}}\right)$, and transverse shear stress $\left(\bar{\tau}_{\mathrm{xz}}=\mathrm{bh} \tau_{\mathrm{xz}}(0,0) / \mathrm{F}_{\mathrm{z}}\right)$ for simply supported beam subjected to a concentrated load for two different aspect ratios $L / h$ [19].

\begin{tabular}{|c|l|l|c|c|c|}
\hline$L / h$ & \multicolumn{1}{|c|}{ Theories } & Model & $\overline{\mathrm{w}^{0}}$ & $\bar{\sigma}_{\mathrm{x}}$ & $\bar{\tau}_{\mathrm{xz}}$ \\
\hline \multirow{3}{*}{4} & Euler-Bernoulli & CLBT & 2.5000 & 6.0000 & - \\
\cline { 2 - 6 } & Timoshenko $[\kappa=5 / 6]$ & FSDBT & 2.9875 & 6.0000 & 0.6000 \\
\cline { 2 - 6 } & Reddy & PSDBT & 2.9739 & 8.3366 & 0.7500 \\
\cline { 2 - 6 } & Touratier & SSDBT & 2.9718 & 8.2399 & 0.7740 \\
\hline \multirow{3}{*}{10} & Euler-Bernoulli & CLBT & 2.5000 & 15.0000 & - \\
\cline { 2 - 6 } & Timoshenko $[\kappa=5 / 6]$ & FSDBT & 2.5780 & 15.0000 & 0.600 \\
\cline { 2 - 6 } & Reddy & PSDBT & 2.5771 & 17.3367 & 0.7500 \\
\cline { 2 - 6 } & Touratier & SSDBT & 2.5769 & 17.2399 & 0.7740 \\
\hline
\end{tabular}




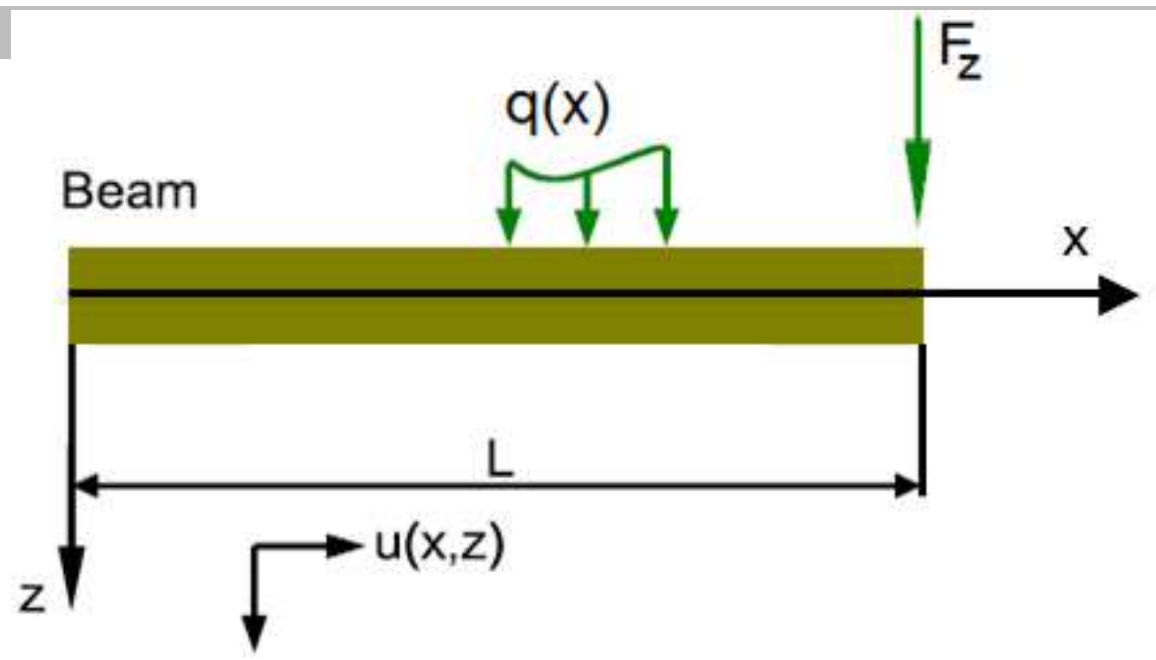

Fig. 1. Loads applied on the beam (general case).

\section{Beam}

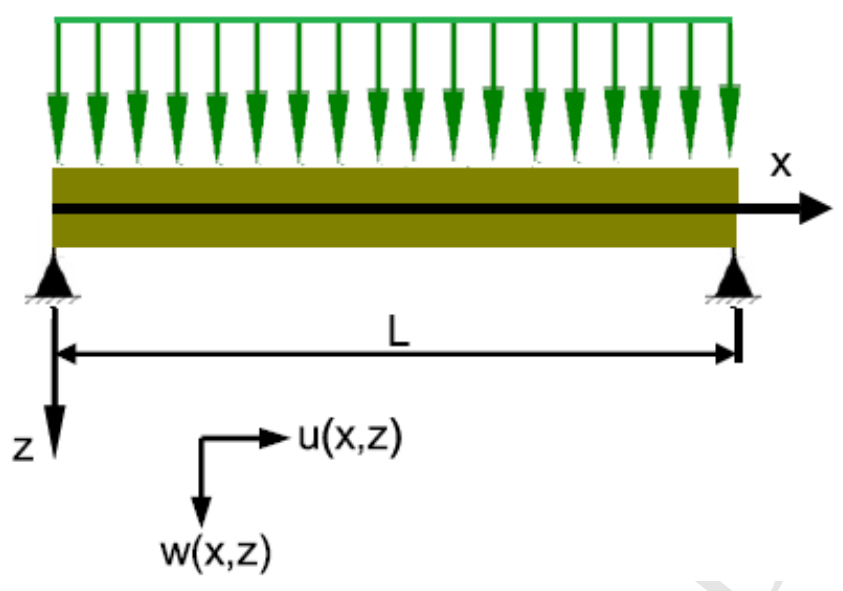

Beam

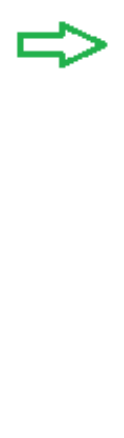

Fig. 2. Uniformly distributed load $\mathrm{q}$ applied on the beam.
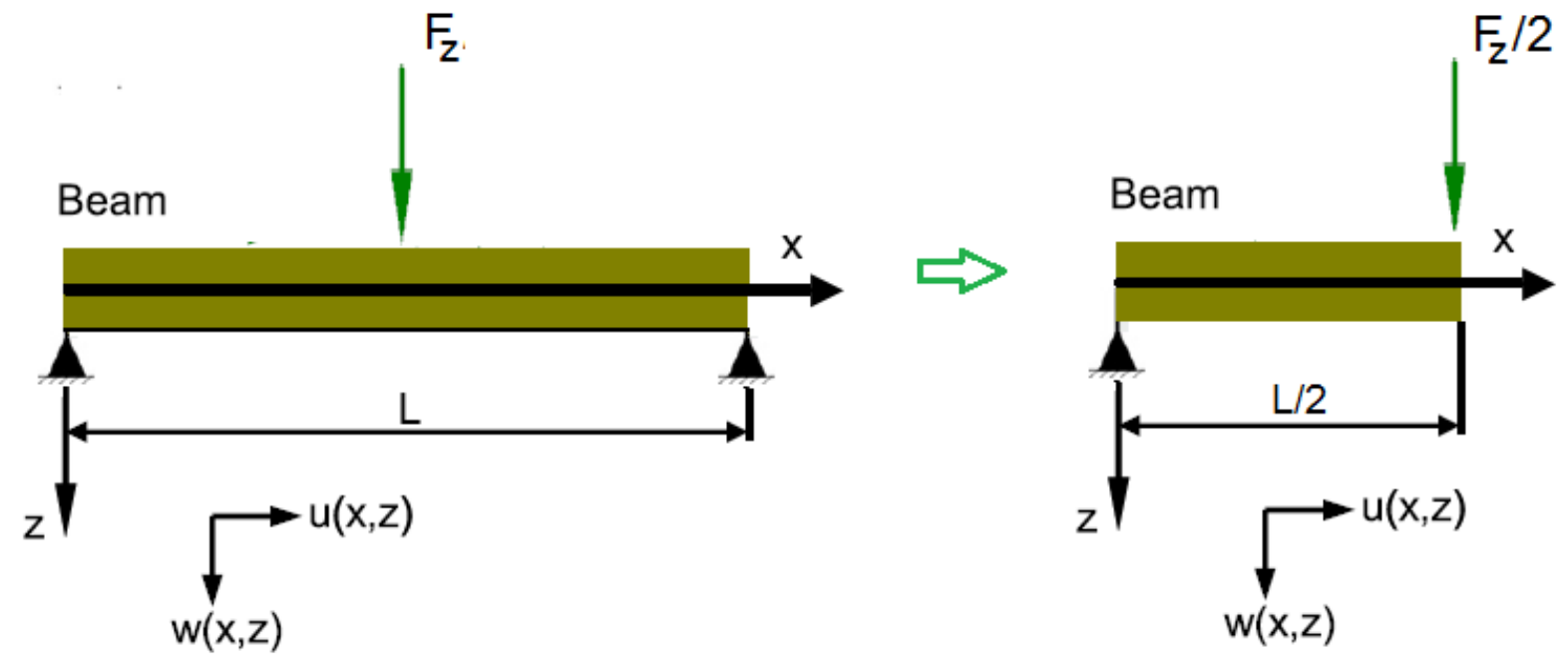

Fig. 3. Central concentrated load $F_{z}$ applied on the beam. 


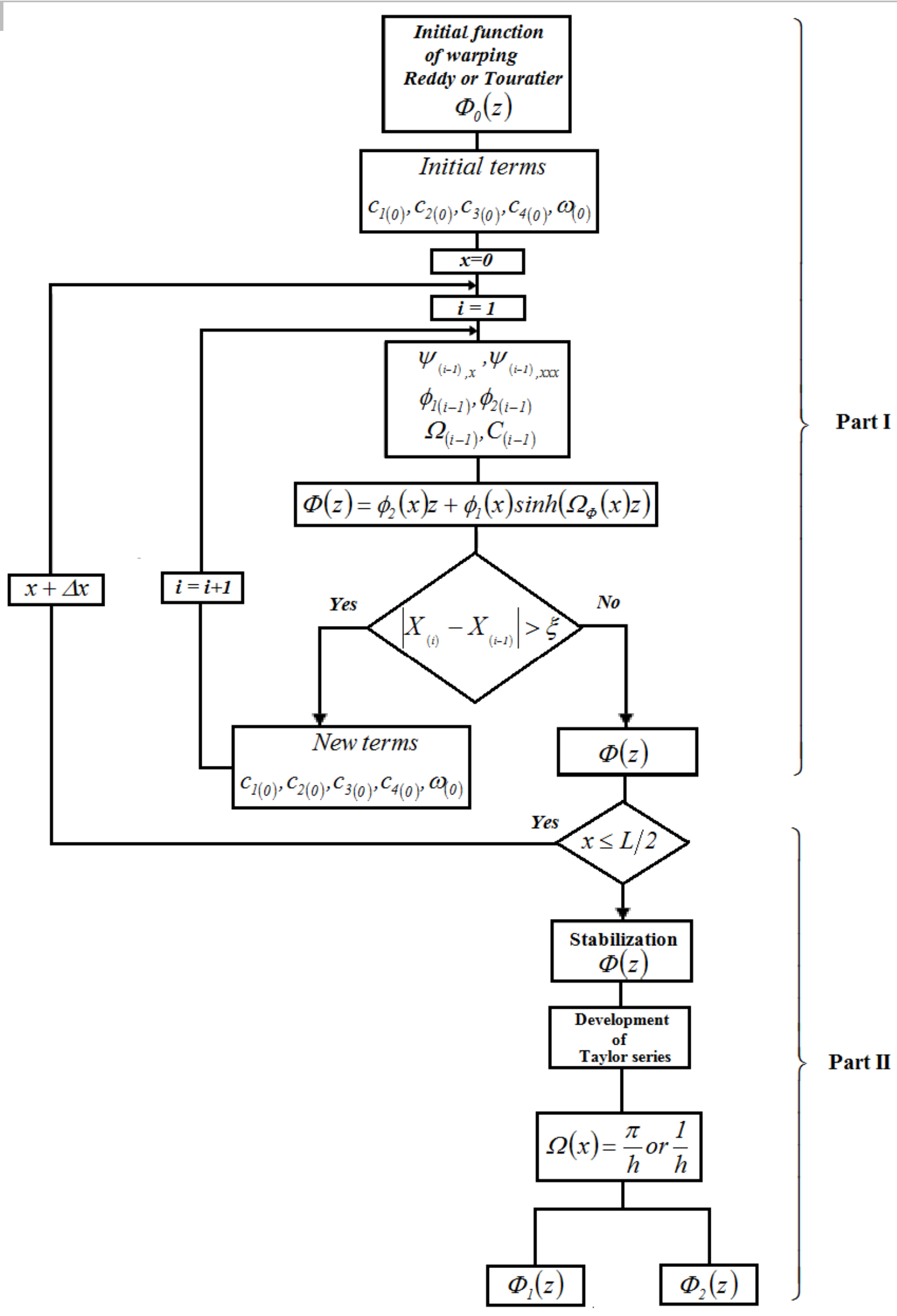

Figure. 4: Diagram of Iterative resolution, part I [35] and part II. 


\section{ACCEPTED MANUSCRIPT}
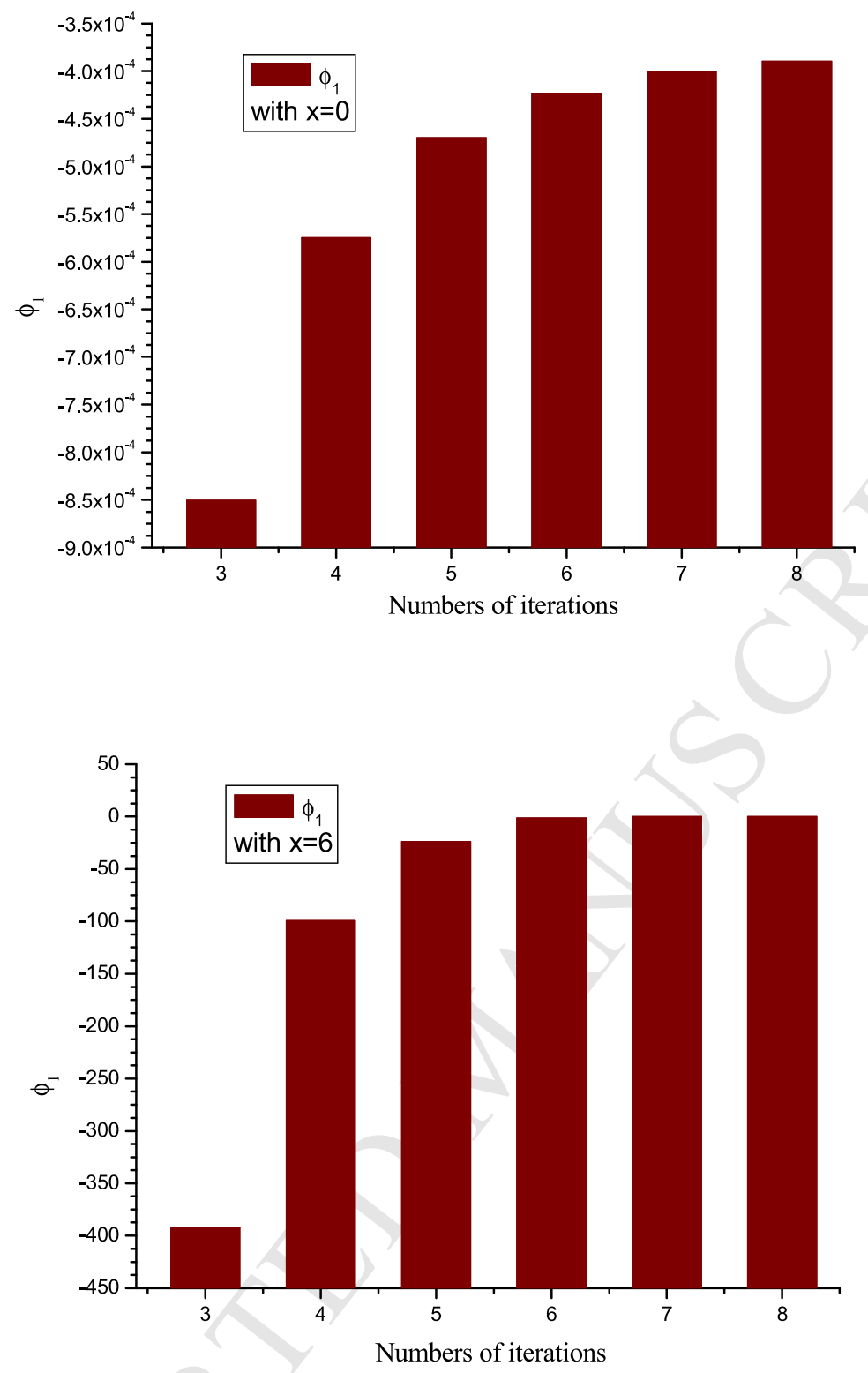

Fig. 5. Convergence of $\phi_{1}$ in function of the iterations at $x=0$ and $x=6$. 

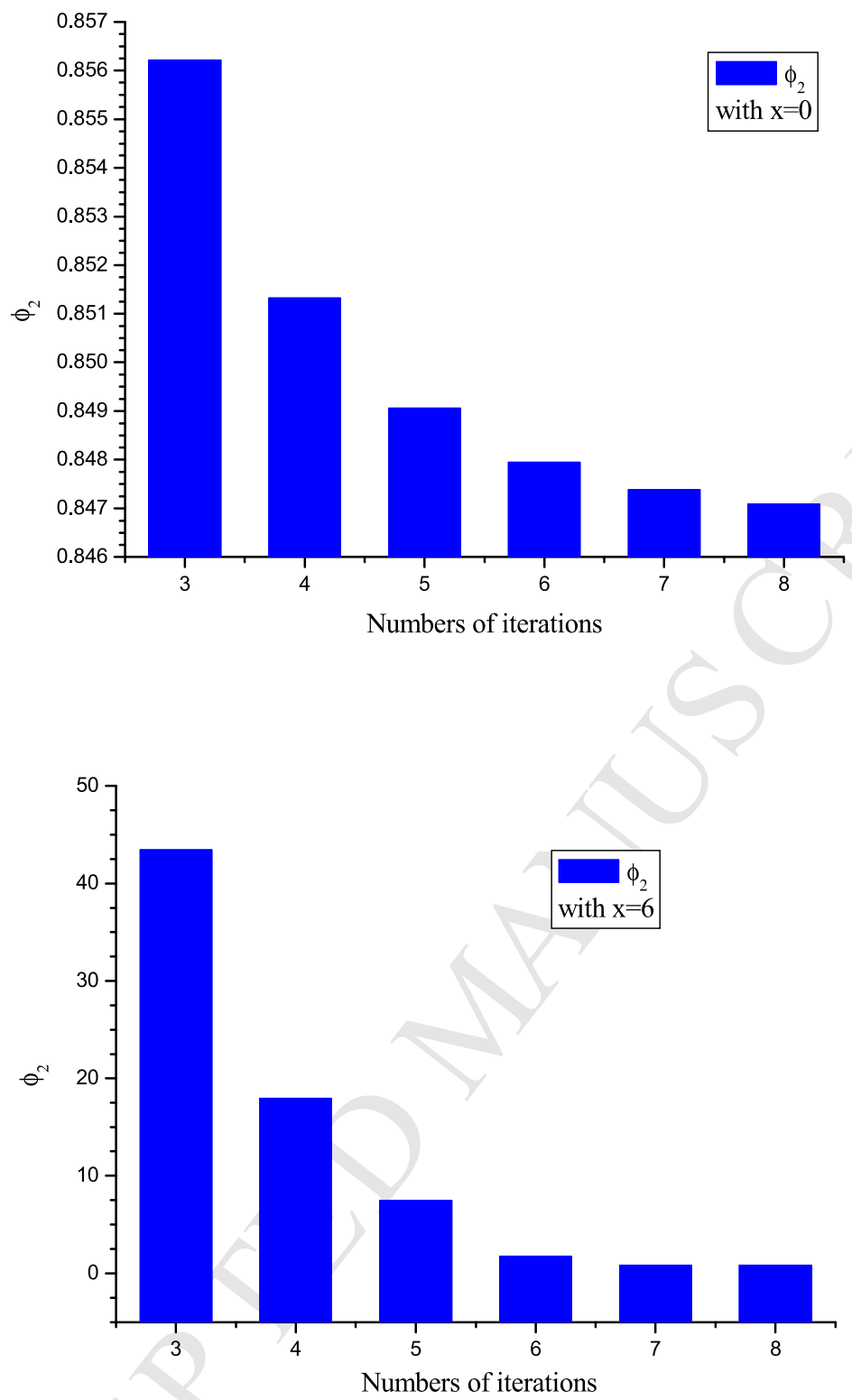

Fig. 6. Convergence of $\phi_{2}$ in function of the number of iterations at $x=0$ and $x=6$. 

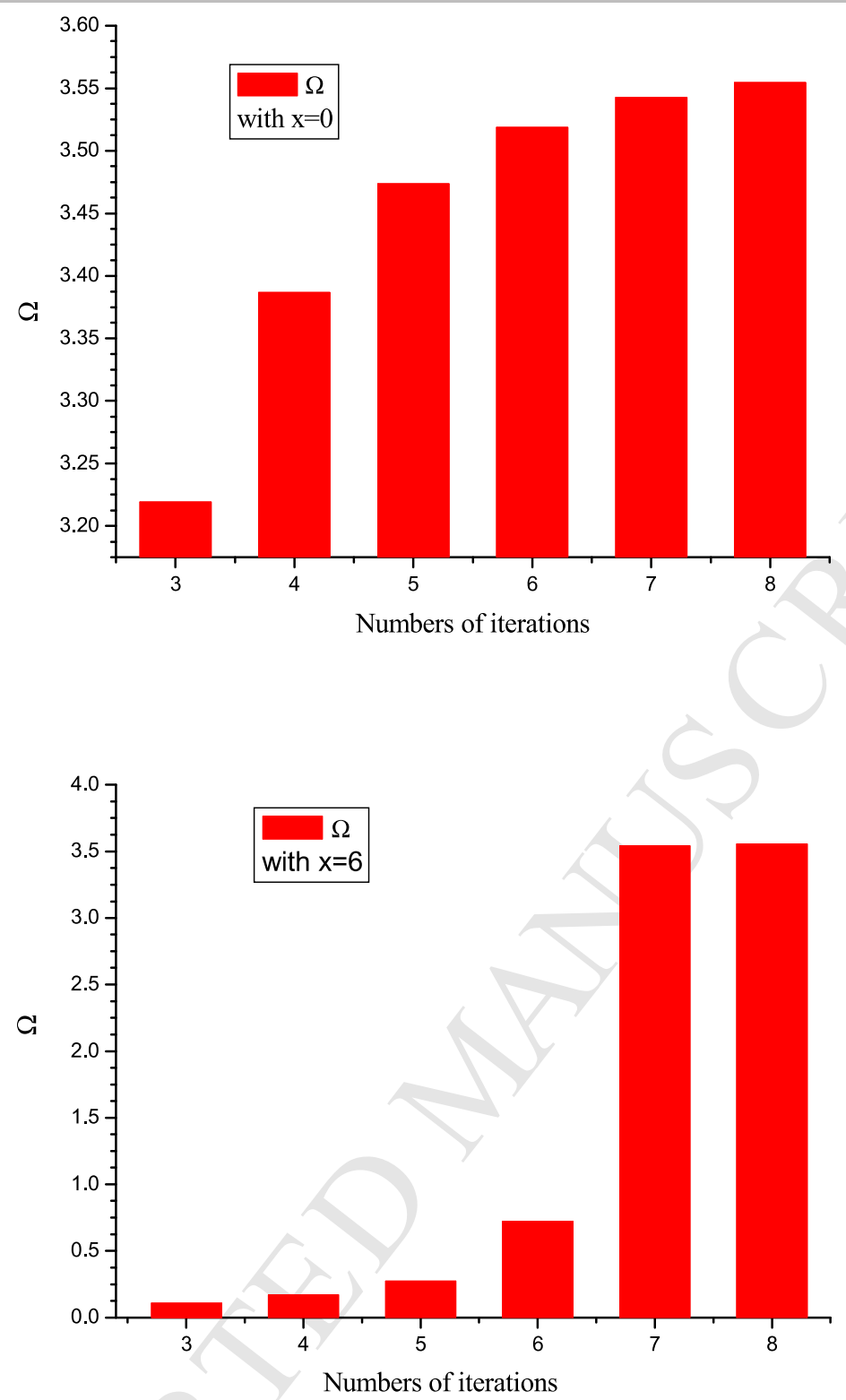

Fig. 7. Convergence of $\Omega$ in function of the numbers of iterations at $\mathrm{x}=0$ and $\mathrm{x}=6$. 


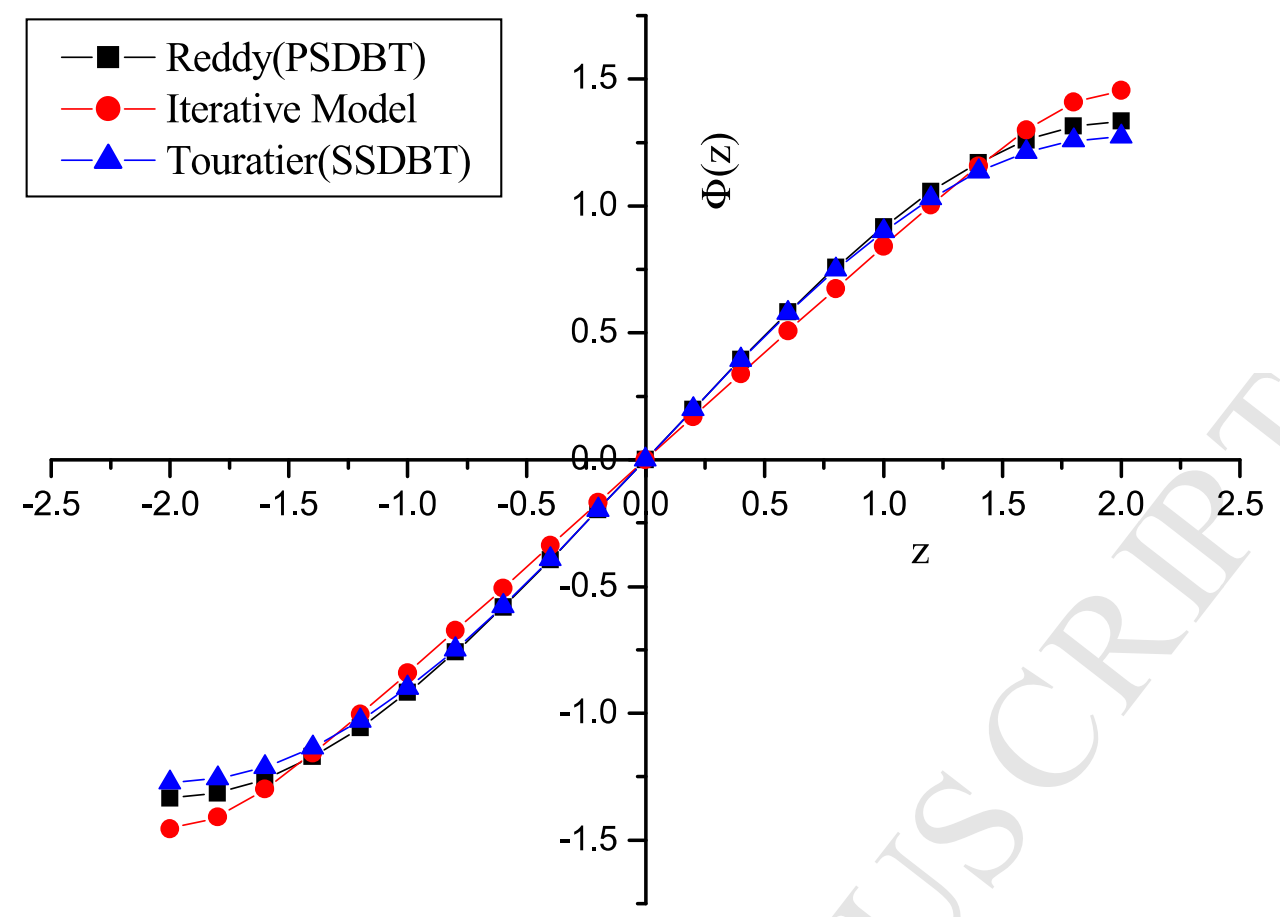

Fig. 8. Comparison of warping functions $\Phi(\mathrm{z})$.

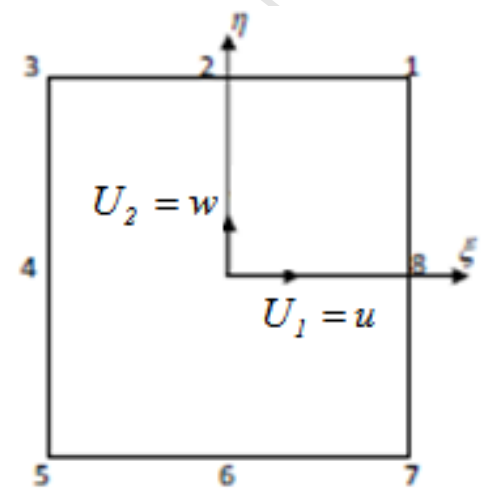

Fig. 9. Eight-nodes isoparametric element. $U 1$ and $U 2$, in the Abaqus notations, stand for $u$ and $w$ respectively 

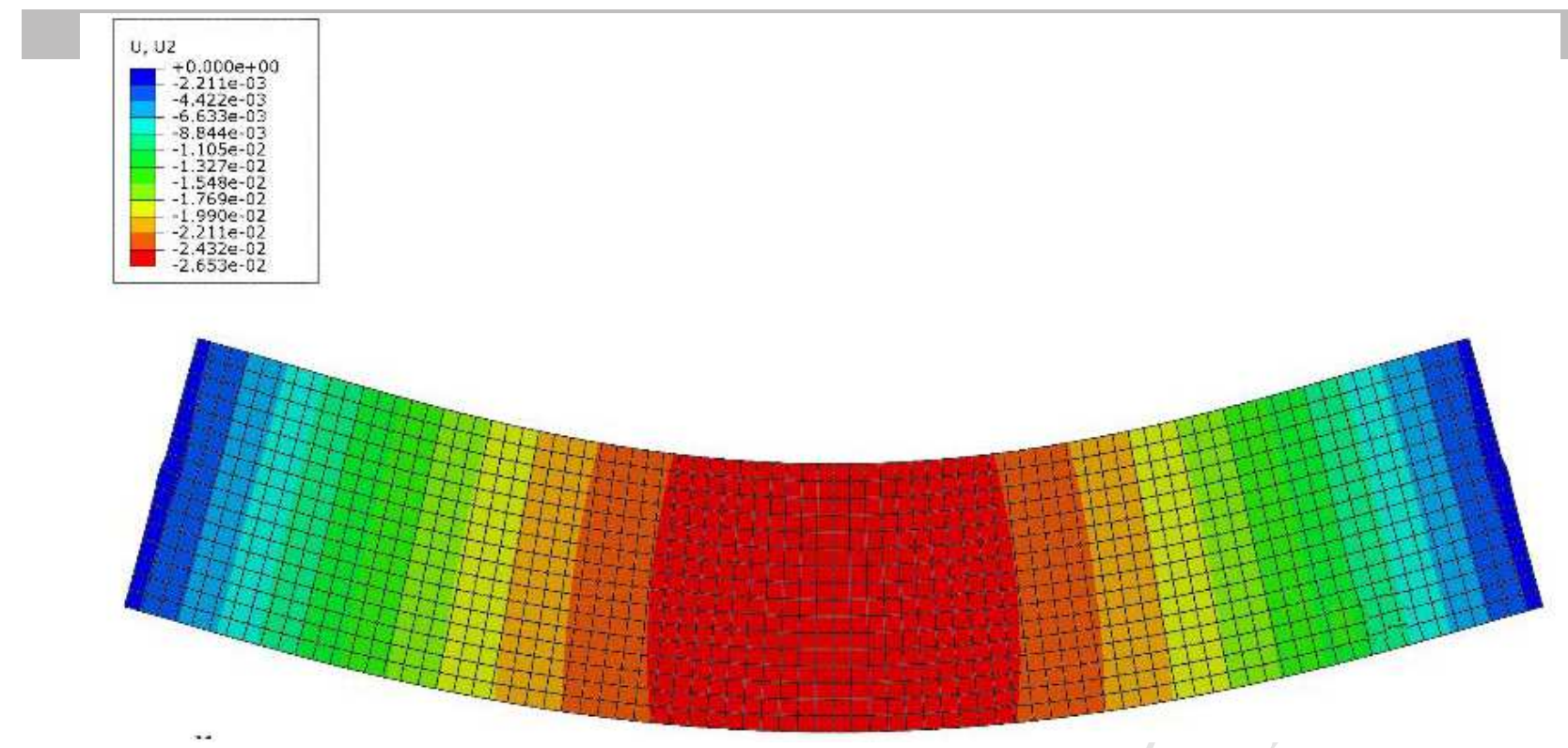

$\mathrm{x}(\mathrm{mm})$

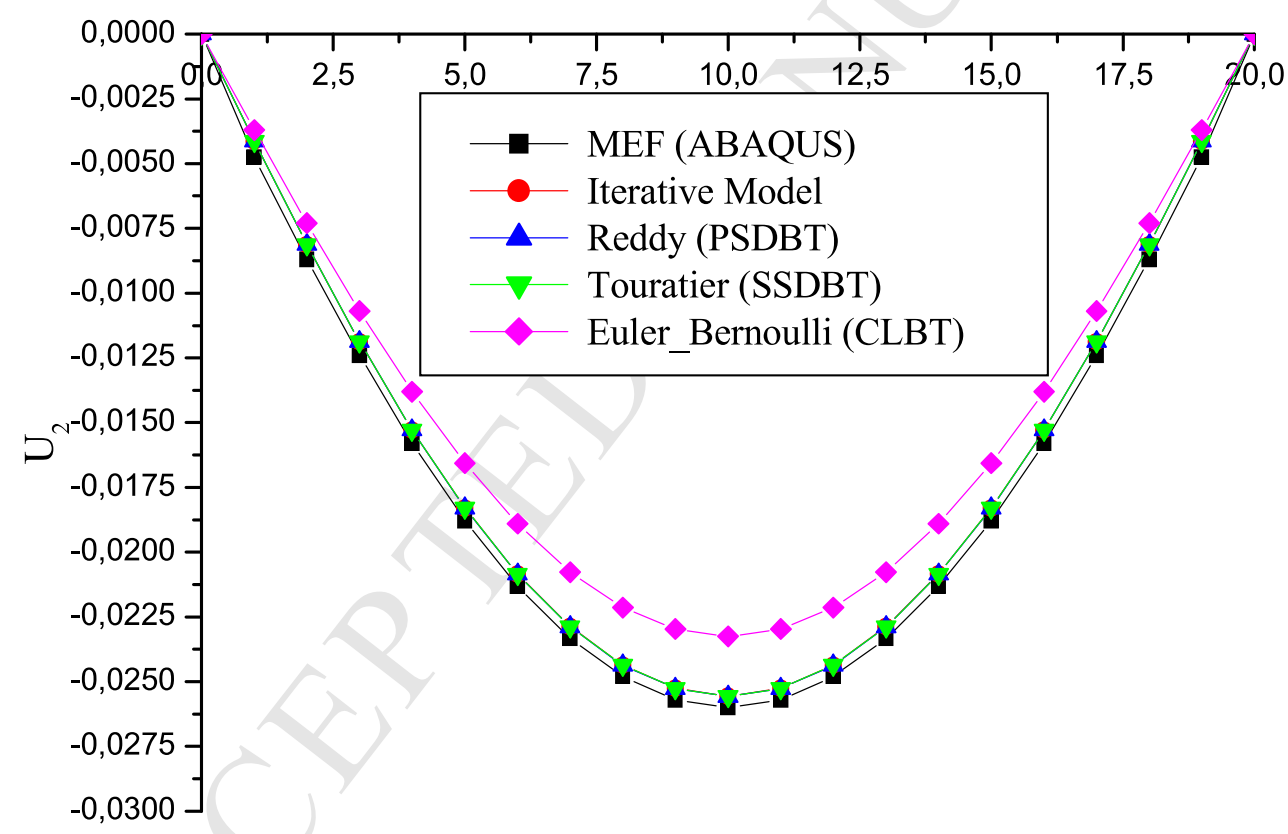

Fig. 10. Variation of the transverse displacement $w(x)=U_{2}$ with different models for isotropic beam under a uniform distributed load $q=250 \mathrm{kN} / \mathrm{m}$. 

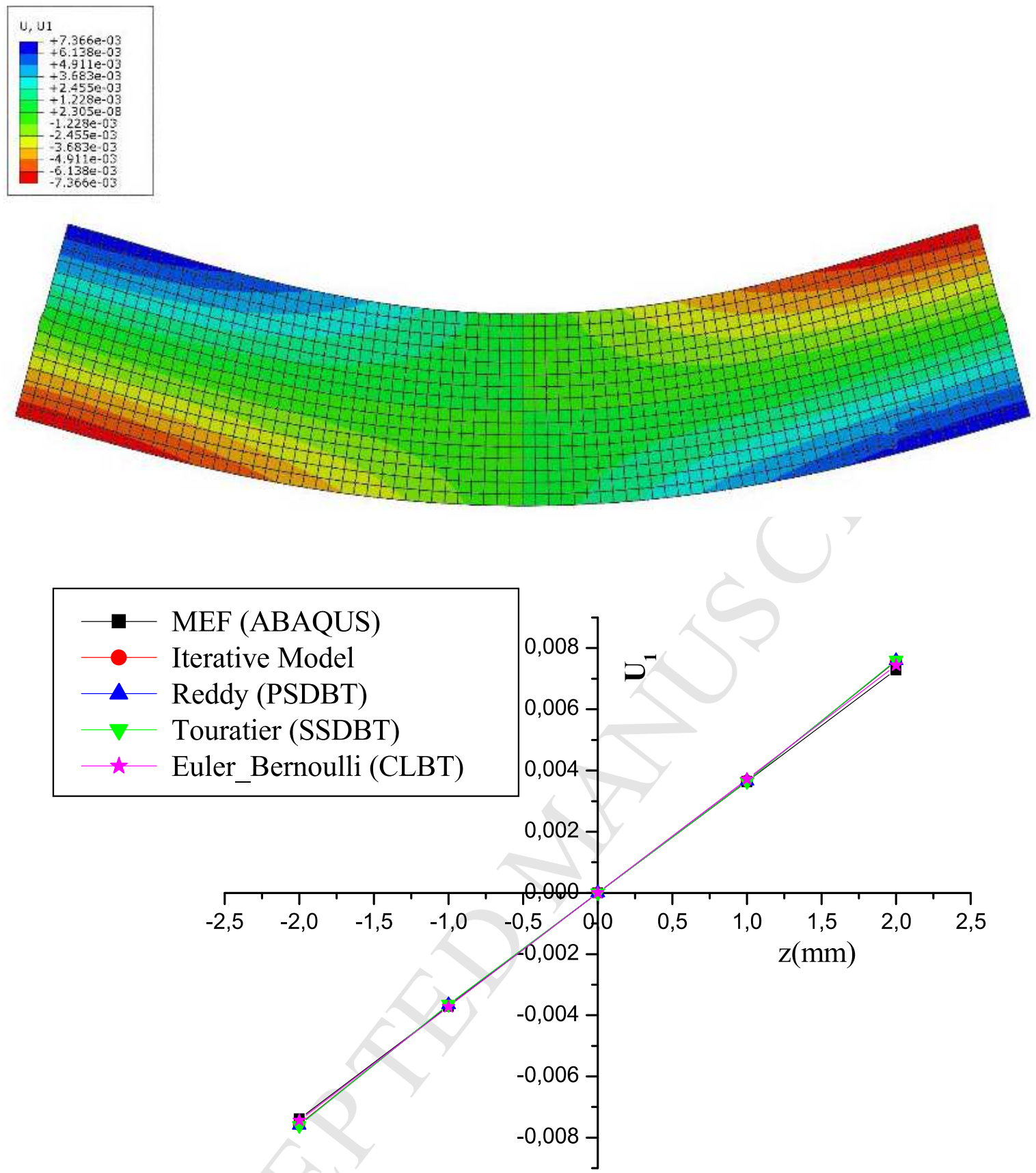

Fig. 11. Variation of the longitudinal displacement $u=U_{1}$ through the thickness with different models for isotropic beam under a uniform load $\mathrm{q}=250 \mathrm{kN} / \mathrm{m}$. 


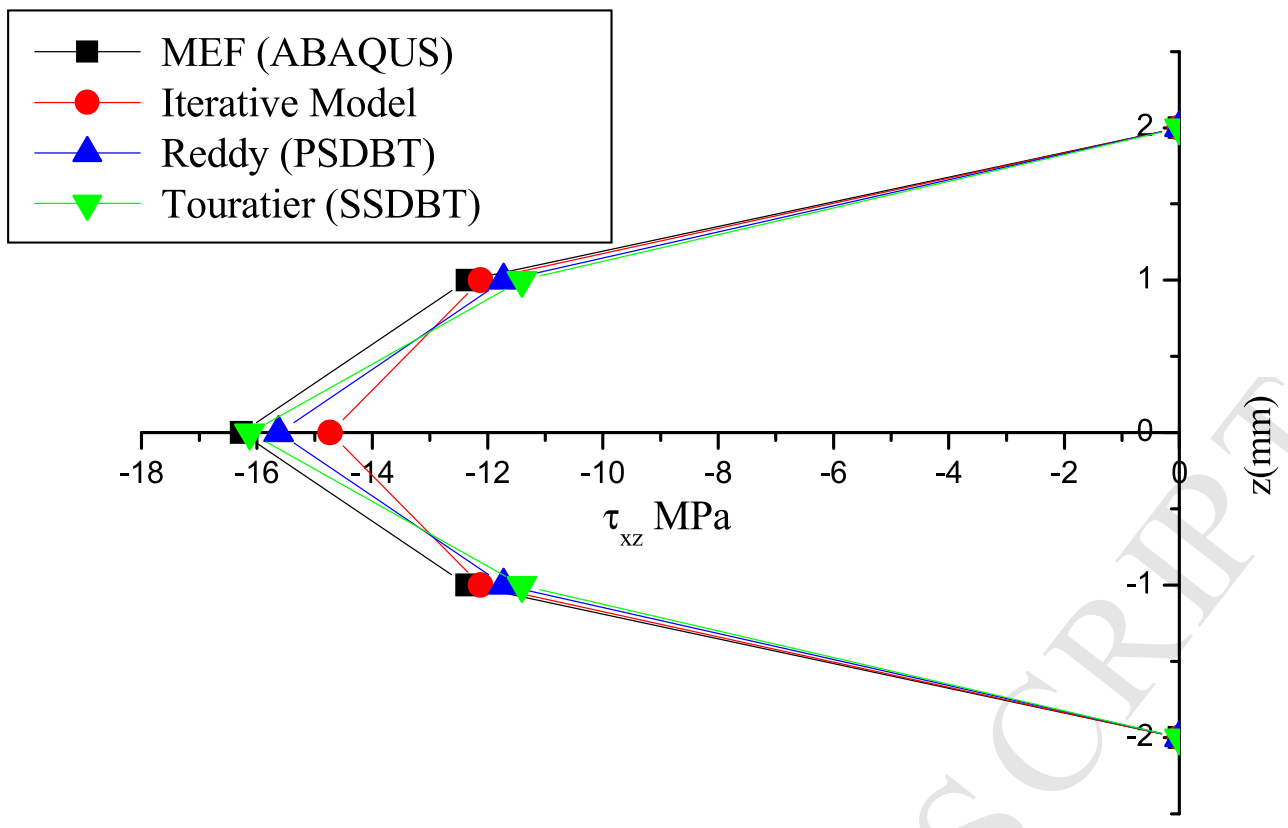

Fig. 12. Variation of the transverse stress $\tau_{x z}$ through the thickness with different models for an isotropic beam under a uniform distributed load $\mathrm{q}=250 \mathrm{kN} / \mathrm{m}$

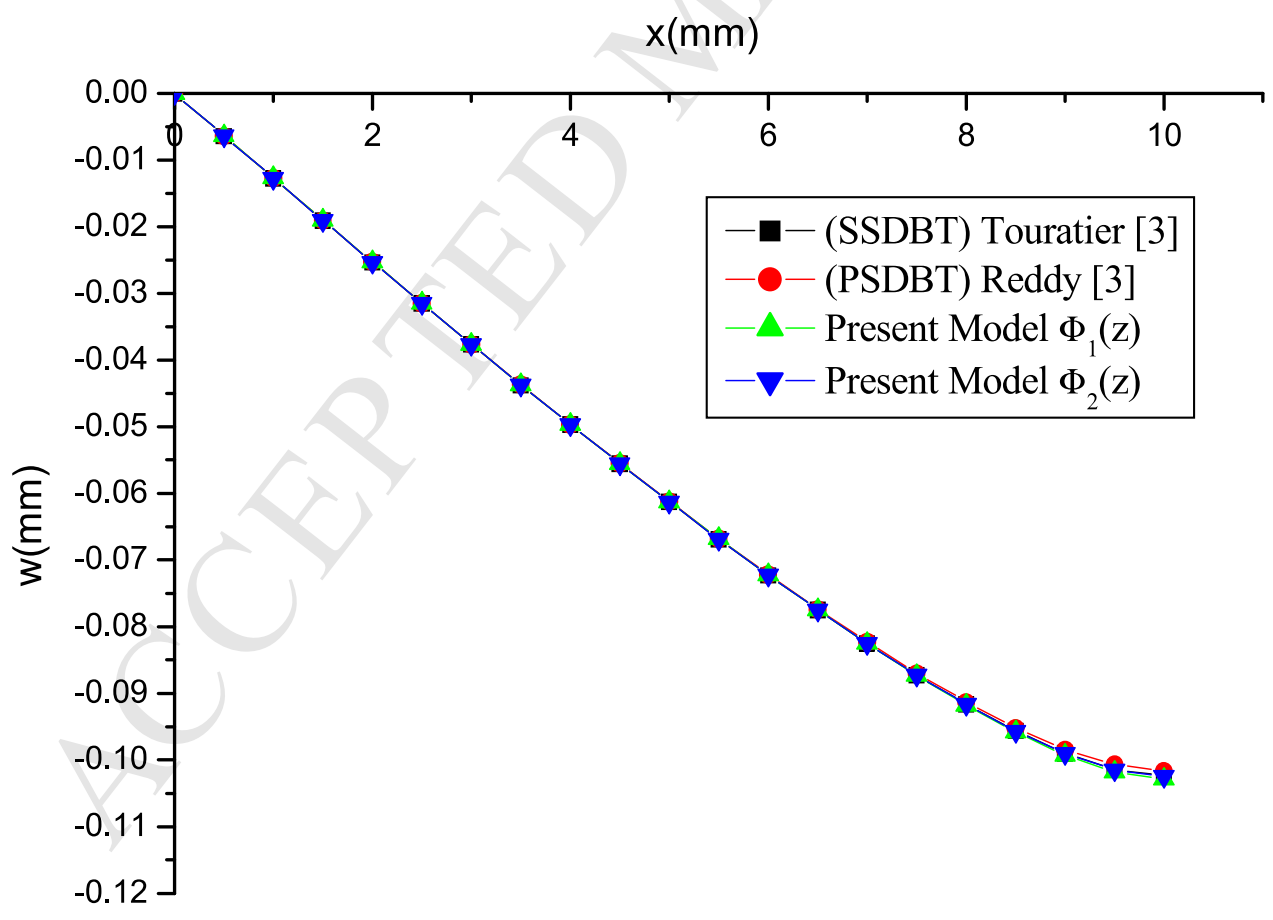

Fig. 13. Variation of the transverse displacement $w(x)$ with different models for an orthotropic beam under three-point bending $\mathrm{F}_{\mathrm{z}}=5 \mathrm{kN}$. 


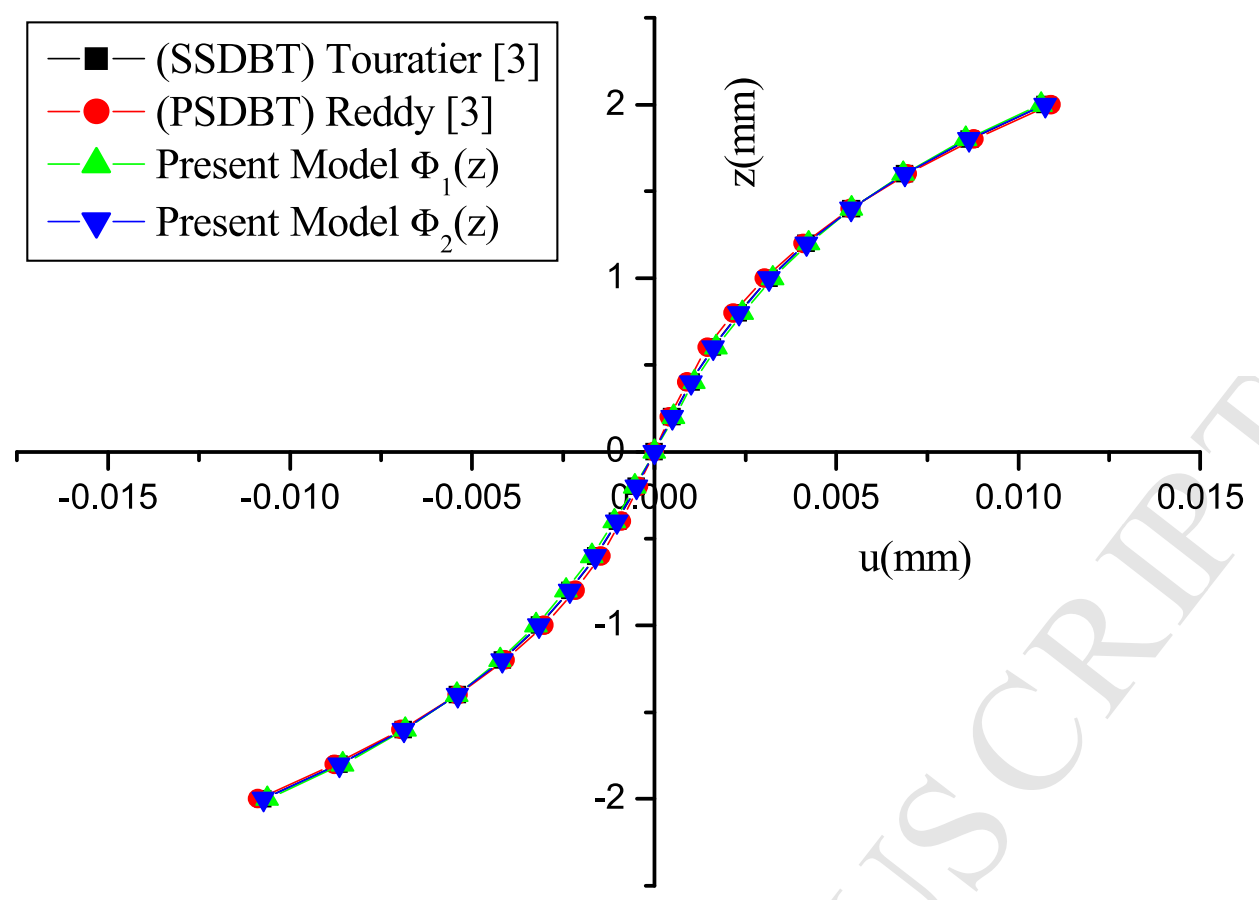

Fig. 14. Variation of the longitudinal displacement $u$ through the thickness with different models for an orthotropic beam under three-point bending $\mathrm{F}_{\mathrm{z}}=5 \mathrm{kN}$.

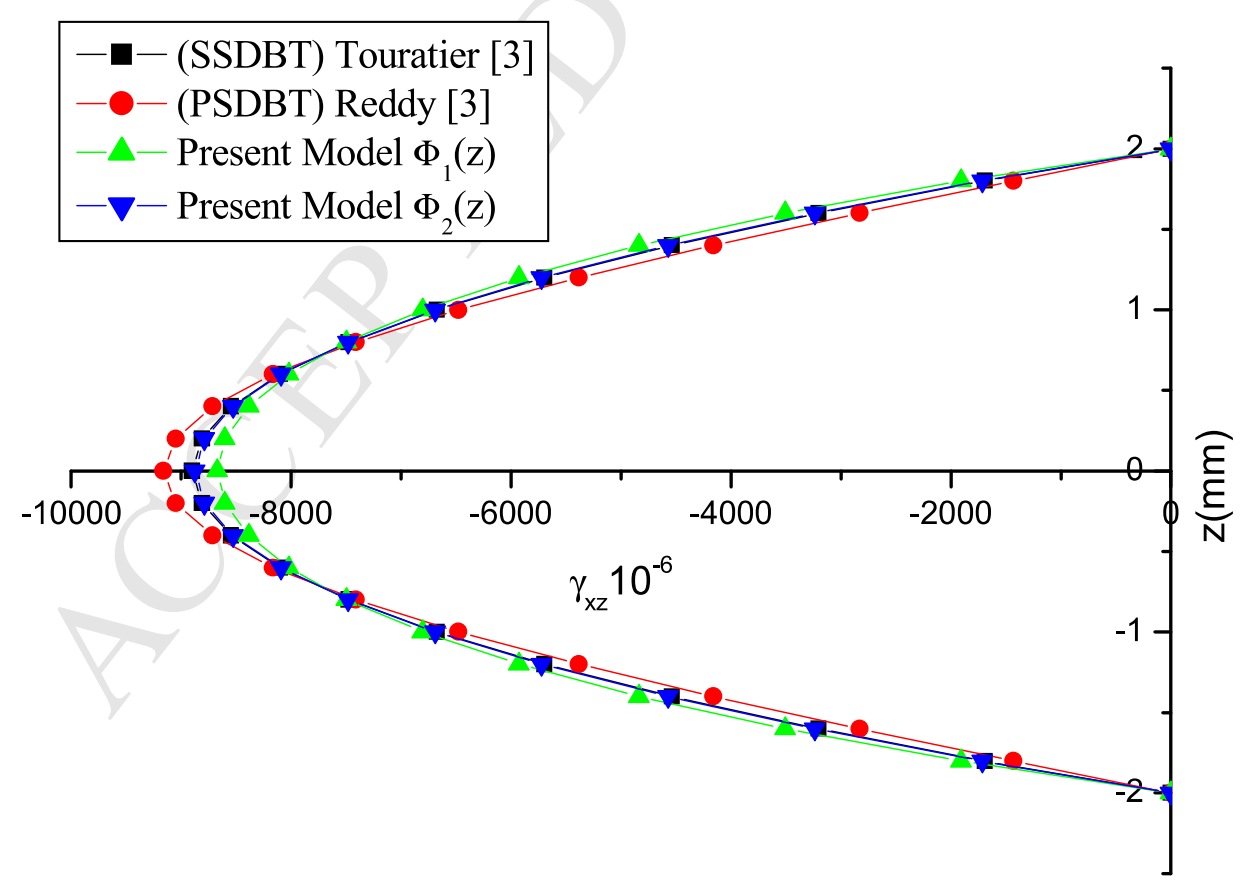

Fig. 15. Variation of the transverse deformation $\gamma_{x z}$ through the thickness with different models for orthotropic beam under three-point bending $\mathrm{F}_{\mathrm{z}}=5 \mathrm{kN}$. 


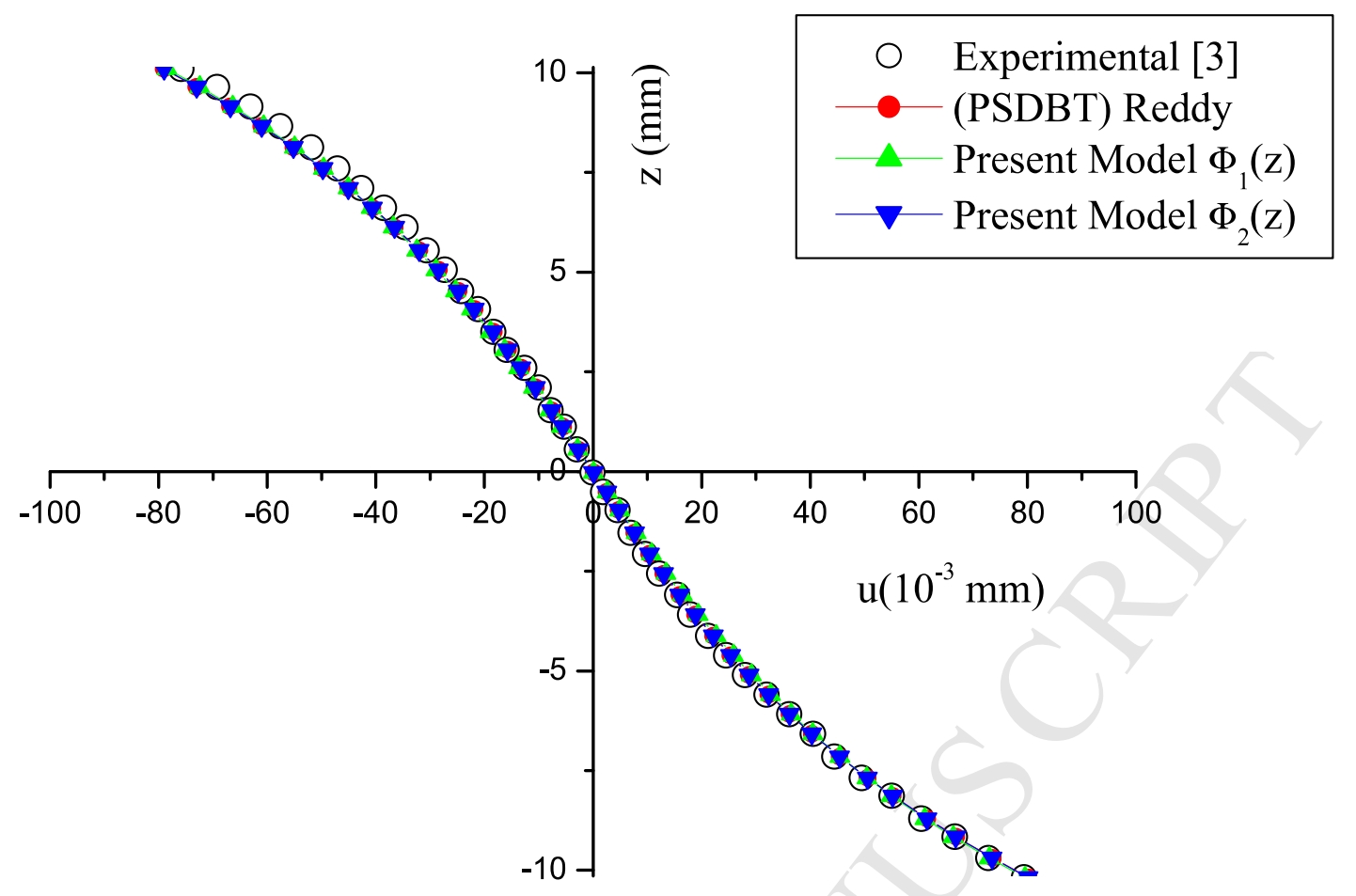

Fig. 16. Variation of the longitudinal displacement $u$ through the thickness with different models for an orthotropic beam under three-point bending $F_{z}=22 \mathrm{kN}$.

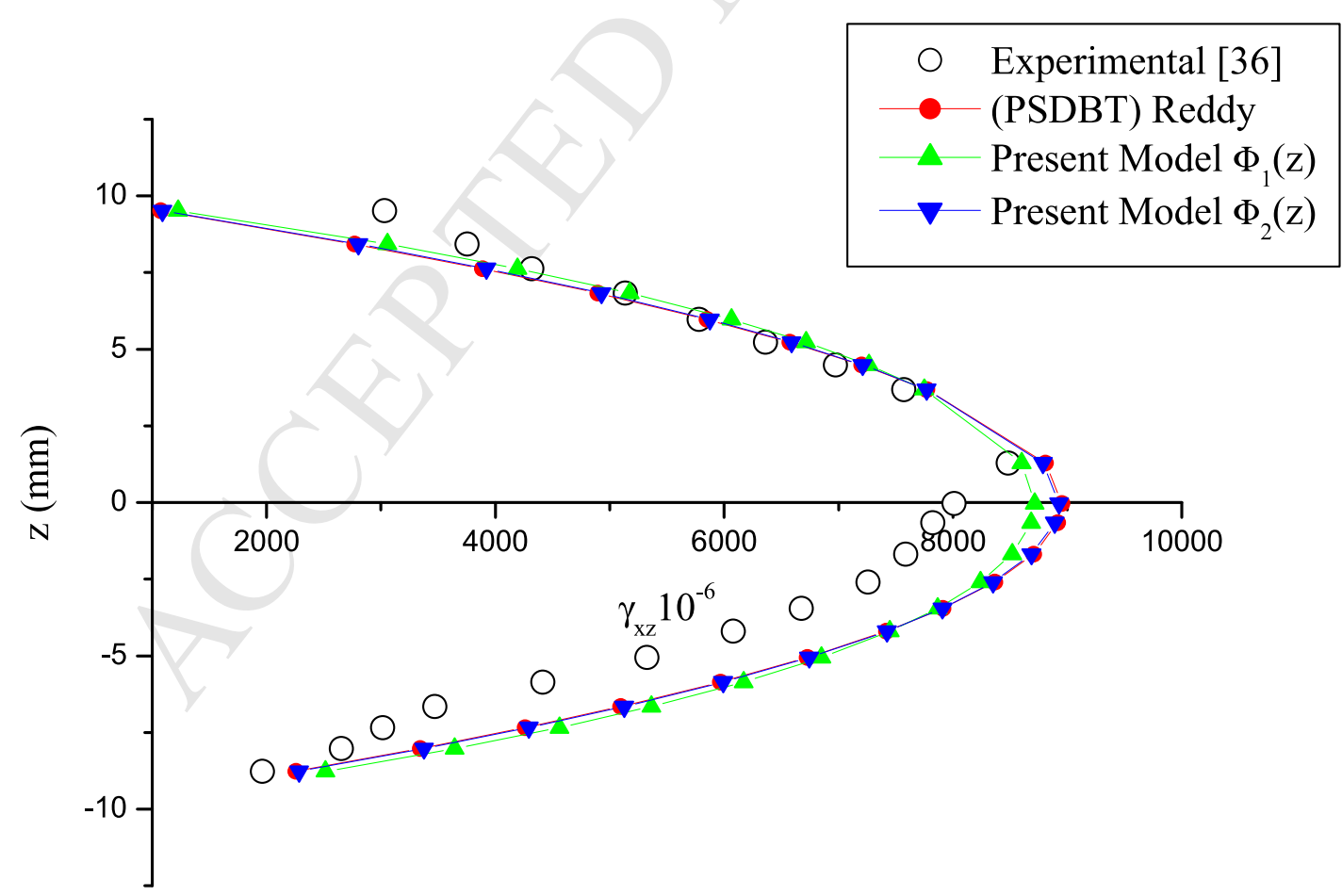

Fig. 17. Variation of the transverse deformation $\gamma_{x z}$ through the thickness with different models for an orthotropic beam under three-point bending $F_{z}=22 \mathrm{kN}$. 